\title{
Active Transition of Fear Memory Phase from Reconsolidation to Extinction through ERK-Mediated Prevention of Reconsolidation
}

\author{
${ }^{\circledR}$ Hotaka Fukushima, ${ }^{1}$ Yue Zhang, ${ }^{1}$ and ${ }^{-}$Satoshi Kida ${ }^{1,2}$ \\ ${ }^{1}$ Department of Bioscience, Faculty of Life Sciences, Tokyo University of Agriculture, Tokyo 156-8502, Japan, and ${ }^{2}$ Graduate School of Agriculture \\ and Life Sciences, The University of Tokyo, Tokyo 113-8657, Japan
}

The retrieval of fear memory induces two opposite memory process, i.e., reconsolidation and extinction. Brief retrieval induces reconsolidation to maintain or enhance fear memory, while prolonged retrieval extinguishes this memory. Although the mechanisms of reconsolidation and extinction have been investigated, it remains unknown how fear memory phases are switched from reconsolidation to extinction during memory retrieval. Here, we show that an extracellular signal-regulated kinase (ERK)-dependent memory transition process after retrieval regulates the switch of memory phases from reconsolidation to extinction by preventing induction of reconsolidation in an inhibitory avoidance (IA) task in male mice. First, the transition memory phase, which cancels the induction of reconsolidation, but is insufficient for the acquisition of extinction, was identified after reconsolidation, but before extinction phases. Second, the reconsolidation, transition, and extinction phases after memory retrieval showed distinct molecular and cellular signatures through cAMP responsive element binding protein (CREB) and ERK phosphorylation in the amygdala, hippocampus, and medial prefrontal cortex (mPFC). The reconsolidation phase showed increased CREB phosphorylation, while the extinction phase displayed several neural populations with various combinations of CREB and/or ERK phosphorylation, in these brain regions. Interestingly, the three memory phases, including the transition phase, showed transient ERK activation immediately after retrieval. Most importantly, the blockade of ERK in the amygdala, hippocampus, or mPFC at the transition memory phase disinhibited reconsolidation-induced enhancement of IA memory. These observations suggest that the ERK-signaling pathway actively regulates the transition of memory phase from reconsolidation to extinction and this process functions as a switch that cancels reconsolidation of fear memory.

Key words: ERK; extinction; fear memory; reconsolidation; transition

Significance Statement

Retrieval of fear memory induces two opposite memory process; reconsolidation and extinction. Reconsolidation maintains/ enhances fear memory, while extinction weakens fear memory. It remains unknown how memory phases are switched from reconsolidation to extinction during retrieval. Here, we identified an active memory transition process functioning as a switch that inhibits reconsolidation. This memory transition phase showed a transient increase of extracellular signal-regulated kinase (ERK) phosphorylation in the amygdala, hippocampus and medial prefrontal cortex (mPFC). Interestingly, inhibition of ERK in these regions at the transition phase disinhibited the reconsolidation-mediated enhancement of inhibitory avoidance (IA) memory. These findings suggest that the transition memory process actively regulates the switch of fear memory phases of fear memory by preventing induction of reconsolidation through the activation of the ERK-signaling pathway.

Received July 17, 2020; revised Nov. 16, 2020; accepted Nov. 23, 2020

Author contributions: S.K. designed research; H.F. and Y.Z. performed research; H.F., Y.Z., and S.K. analyzed data; S.K. wrote the paper.

S.K. was supported by Grants-in-Aids for Scientific Research (A) 15H02488, 18H03944, and 19H01047; Scientific Research (B) 23300120 and 20380078; and Challenging Exploratory Research 24650172, 26640014, 17K19464, and 20K21265; Grants-in-Aids for Scientific Research on Priority Areas-Molecular Brain Science 18022038 and 22022039; Grants-in-Aid for Scientific Research on Innovative Areas (research in a proposed research area) 24116008, 24116001, 23115716, 17H06084, 17H05961, 17H05581, 18H05428, 18H05434, and 19H04917; the MEXT-Supported Program for the Strategic Research Foundation at Private Universities Grant S1311017; Core Research for Evolutional Science and Technology (CREST),
Japan; The Sumitomo Foundation, Japan; the Takeda Science Foundation, Japan; The Naito Foundation, The Uehara Memorial Foundation, Daiichi Sankyo Foundation of Life Science, The Food Science Institute Foundation (Ryoushoku-kenkyukai), and The Science Research Promotion Fund; and The Promotion and Mutual Aid Corporation for Private Schools of Japan. H.F. was supported by Grant-in-Aid for Scientific Research on Innovative Areas $17 \mathrm{H} 05962$.

The authors declare no competing financial interests.

Correspondence should be addressed to Satoshi Kida at akida@g.ecc.u-tokyo.ac.jp.

https://doi.org/10.1523/JNEUROSCI.1854-20.2020

Copyright $\odot 2021$ the authors 


\section{Introduction}

Memory retrieval is not a passive process, but is rather, a dynamic process that allows the maintenance, strengthening, weakening, or altering/updating of an original memory (Misanin et al., 1968; Schneider and Sherman, 1968; Lewis, 1979; Mactutus et al., 1979; Gordon, 1981; Nader et al., 2000; Nader and Hardt, 2009; Dudai, 2012; Fukushima et al., 2014). Importantly, a retrieved conditioned fear memory by brief re-exposure to the conditioned stimulus (CS) becomes labile and requires gene expression-dependent reconsolidation for its maintenance or enhancement (Nader et al., 2000; Dudai, 2002; Kida et al., 2002; Suzuki et al., 2004; Tronel et al., 2005; Fukushima et al., 2014). Conversely, continuous or repeated re-exposure to the CS induces memory extinction, which weakens fear memory (Pavlov, 1927; Rescorla, 2001; Myers and Davis, 2002). Thus, the retrieval of fear memory induces two opposite memory processes, i.e., reconsolidation and extinction, although both processes are induced by re-exposure to an identical CS, but differ according to the duration of re-exposure to the CS.

The common and critical biochemical feature of reconsolidation and extinction is the requirement for cAMP responsive element binding protein (CREB)-mediated gene expression (Mamiya et al., 2009). Interestingly, we have shown contrasting molecular, anatomic and behavioral signatures between the reconsolidation and extinction phases of contextual fear memory (Suzuki et al., 2004; Mamiya et al., 2009). Blocking protein synthesis during the reconsolidation phase disrupts the original fear memory, whereas blocking protein synthesis during the extinction phase fails to do this, although the contextual fear memory was reactivated. The requirement of brain regions displaying the activation of CREB-mediated gene expression differs between reconsolidation and extinction; reconsolidation depends on the amygdala and hippocampus, whereas extinction relies on the amygdala and medial prefrontal cortex (mPFC). However, the time course of amygdaloid CREB activation differs between the reconsolidation and extinction memory phases. These observations suggested that the reconsolidation and extinction phases are not independent, but rather interacts with each other. Interestingly, recent studies have identified a time window (transition phase) that shows no extracellular signal-regulated kinase (ERK) activation in the amygdala after reconsolidation, but before the extinction phases following the retrieval of an auditory fear memory (Merlo et al., 2018). Taken together, these findings suggest the possible mechanisms by which memory phases are switched from reconsolidation to extinction during the retrieval of fear memory. In other words, it is possible that the memory transition process actively regulates this switch.

In an inhibitory avoidance (IA) task, mice receive an electrical footshock after they enter a dark compartment from a light compartment and form a memory to avoid the dark compartment. Previously, by using this task, we showed that the reconsolidation and extinction phases can be discriminated at the time point when a mouse enters a dark compartment from a light compartment during a re-exposure session (Fukushima et al., 2014). Therefore, this task allows us to characterize the perspective molecular signatures of the reconsolidation and extinction phases, in contrast to the classical contextual fear conditioning paradigm in which the reactivation of a conditioned fear memory by re-exposure to the CS initiates both reconsolidation and extinction; short ( $3 \mathrm{~min}$ ) re-exposure to the conditioned context induces reconsolidation, whereas long $(30 \mathrm{~min})$ or repeated re-exposure to this context induces extinction (Eisenberg et al., 2003;
Pedreira and Maldonado, 2003; Suzuki et al., 2004; Lee et al., 2008; Mamiya et al., 2009). Furthermore, we found that the retrieved IA memory is enhanced through memory reconsolidation in this task (Fukushima et al., 2014).

To understand the mechanism of for the transition from reconsolidation to extinction during the retrieval of fear memory, we aimed to identify and characterize the molecular, cellular and behavioral signatures of the reconsolidation, transition, and extinction phases of IA memory. We analyzed the activation of CREB and ERK in the amygdala, hippocampus, and mPFC in the reconsolidation, transition and extinction phases and examined the roles of ERK activation in these memory processes.

\section{Materials and Methods \\ Mice}

All experiments were conducted according to the Guide for the Care and Use of Laboratory Animals (Japan Neuroscience Society and Tokyo University of Agriculture). All animal experiments performed in this study were approved by the Animal Care and Use Committee of Tokyo University of Agriculture (authorization \#280037). All surgical procedures were performed under Nembutal anesthesia and every effort was made to minimize suffering. Male C57BL/6N mice were obtained from Charles River. The mice were housed in cages of five or six, maintained on a 12/12 h light/dark cycle, and allowed access to food and water ad libitum. The mice were at least eight weeks of age when tested. Testing was performed during the light phase of the cycle. All experiments were conducted blind to the treatment condition of the mice.

\section{IA test}

The step-through IA apparatus (OHARA Pharmaceutical) consisted of a box with separate light and dark compartments (both $15.5 \times 12.5 \times$ $11.5 \mathrm{~cm}$ ). The light compartment was illuminated by a fluorescent light (2500 lux; Fukushima et al., 2008, 2014; Zhang et al., 2011; Ishikawa et al., 2016). Before the commencement of IA training, the mice were handled individually for $2 \mathrm{~min}$ each day for one week. During the training sessions, each mouse was allowed to habituate to the light compartment for $30 \mathrm{~s}$, and the guillotine door was raised to allow access to the dark compartment. Latency to enter the dark compartment was considered as a measure of acquisition. As soon as the mouse had entered the dark compartment, the guillotine door was closed. After $5 \mathrm{~s}$, a footshock $(0.2 \mathrm{~mA})$ was delivered for a total period of $2 \mathrm{~s}$ (training). At $24 \mathrm{~h}$ after the training session, the mouse was placed back in the light compartment until it entered the dark compartment (average $459 \pm 15.49$ s). Immediately after the mouse had entered the dark compartment, the guillotine door was closed and the mouse stayed in the dark compartment for a varying length of time $(0,1$, or $10 \mathrm{~min})$ without a footshock (reactivation). Memory was assessed at $48 \mathrm{~h}$ later [postreactivation longterm memory (PR-LTM) test] as the crossover latency for the mouse to enter the dark compartment when replaced in the light compartment, as in reactivation.

For the first experiment, we examined the effect of protein synthesis inhibition after reactivation (re-exposure to the dark compartment for 0 , 1 or 10 min; Fig. 1). The protein synthesis inhibitor anisomycin (ANI; Wako) was dissolved in saline ( $\mathrm{pH}$ adjusted to 7.0-7.4 with $\mathrm{NaOH}$ ). The mice were trained as described above, and at $24 \mathrm{~h}$ later, they received vehicle (VEH) or ANI $(150 \mathrm{mg} / \mathrm{kg}$, i.p.) immediately after re-exposure to the dark compartment for 0,1 , or 10 min without a footshock (reactivation). At this dose, ANI inhibits $>90 \%$ of protein synthesis in the brain during the first $2 \mathrm{~h}$ (Flood et al., 1973). At $48 \mathrm{~h}$ after the reactivation session, individual mice were once again placed in the light compartment and crossover latency was assessed.

For the second experiment [phosphorylated CREB (pCREB) and phosphorylated ERK (pERK) immunohistochemistry; Figs. 2-5], we examined the brain regions that were activated after re-exposure to the light (until the mice entered the dark compartment, re-exposure to the dark compartment for $0 \mathrm{~min}$ ) or dark compartment (re-exposure to the dark compartment for 1 or $10 \mathrm{~min}$ ). The mice were divided into four 
groups. At $24 \mathrm{~h}$ after training, individual mice were re-exposed to the light compartment and then stayed in the dark compartment following their entry from the dark compartment [reactivation: $0 \mathrm{~min}$ in the dark compartment, reconsolidation (Recon) group; $1 \mathrm{~min}$, transition (Tran) group; $10 \mathrm{~min}$, extinction (Ext) group]. Another group of mice were not returned to the light/dark compartment [non-reactivated (NR) group]. The mice were then anesthetized with Nembutal $(750 \mathrm{mg} / \mathrm{kg}$, i.p.) at 5 , 15 , or $30 \mathrm{~min}$ after reactivation.

For the third experiment (microinfusion of U0126; Figs. 6,7), we examined the effects of ERK inhibition in the amygdala, hippocampus, or $\mathrm{mPFC}$ on memory reconsolidation/enhancement, transition, and extinction. The MEK inhibitor U0126 (Sigma-Aldrich) was dissolved in artificial cerebrospinal fluid containing three drops of Tween 80 (Sigma) in $2.5 \mathrm{ml}$ of $7.5 \%$ dimethyl sulfoxide (Wako) and adjusted to $\mathrm{pH} 7.4$ with $\mathrm{NaOH}$. The mice were trained as described above, and at $24 \mathrm{~h}$ later, they were placed back in the light compartment (reactivation). The mice were microinfused with U0126 $(1 \mu \mathrm{g})$ or VEH into the various brain regions immediately after (Figs. $6 A, C, E-H, 7 A-C$ ) or at $30 \mathrm{~min}$ after (Fig. $6 B, D$ ) reactivation. At $48 \mathrm{~h}$ after reactivation, individual mice were once again placed in the light compartment and crossover latency was assessed (PRLTM). Microinfusions into the hippocampus and mPFC $(0.5 \mu \mathrm{l})$ were made at a rate of $0.25 \mu \mathrm{l} / \mathrm{min}$. Microinfusions into the amygdala $(0.2 \mu \mathrm{l})$ were made at a rate of $0.1 \mu \mathrm{l} / \mathrm{min}$. The injection cannula was left in place for $2 \mathrm{~min}$ after microinfusion and the mice were then returned to their home cages. The MEK inhibitor SL327 (Santa Cruz Biotechnology) was dissolved in dimethyl sulfoxide and diluted with saline. The mice were trained as described above, and at $24 \mathrm{~h}$ later, individual mice were placed back in the light compartment (reactivation). The mice were systemically injected with SL327 (10 or $20 \mathrm{mg} / \mathrm{kg}$ ) or VEH immediately after reactivation (Fig. $7 D-F)$. At $48 \mathrm{~h}$ after reactivation, individual mice were once again placed in the light compartment and crossover latency was assessed (PR-LTM).

\section{Immunohistochemistry}

Immunohistochemistry was performed as described previously (Mamiya et al., 2009; Suzuki et al., 2011; Zhang et al., 2011; Fukushima et al., 2014; Ishikawa et al., 2016; Hasegawa et al., 2019). After anesthetization, all mice were perfused with $4 \%$ paraformaldehyde. The brains were removed, fixed overnight, transferred to $30 \%$ sucrose, and stored at $4^{\circ} \mathrm{C}$. Coronal sections $(30 \mu \mathrm{m})$ were cut in a cryostat.

For pCREB and pERK staining, free-floating sections were treated with $1 \% \mathrm{H}_{2} \mathrm{O}_{2}$ and incubated overnight with a rabbit polyclonal antiphospho-CREB (serine 133; S133) antibody (1:1000; \#06-519, Millipore) and/or rabbit monoclonal anti-phospho-ERK1/2 (T202/Y204) antibody (1:300; \#4370; Cell Signaling Technology) in blocking solution (phosphate-buffered saline plus $1 \%$ goat serum albumin, $1 \mathrm{mg} / \mathrm{ml}$ bovine serum albumin, and $0.05 \%$ Triton $\mathrm{X}-100$ ). The sections were washed with phosphate-buffered saline and incubated with horseradish peroxidase-conjugated donkey anti-rabbit IgG (1:500; Jackson ImmunoResearch) for pCREB or horseradish peroxidaseconjugated goat anti-rabbit IgG for pERK for $1 \mathrm{~h}$ at room temperature. pCREB signals were amplified by biotin tyramide and visualized using Alexa Fluor-conjugated streptavidin (Invitrogen). pERK signals were amplified with TSA-FCM (Invitrogen). The sections were mounted on slides and coverslipped using mounting medium (Millipore).

\section{Quantification}

Quantification was performed as described previously (Frankland et al., 2006; Fukushima et al., 2014; Mamiya et al., 2009; Zhang et al., 2011; Suzuki et al., 2008). Structures were defined anatomically according to the atlas of Franklin and Paxinos (1997). All immunoreactive neurons were counted by an experimenter blind to the treatment condition.

Fluorescence images were acquired using an FV300 (Olympus) or TCS SP8 (Leica) confocal microscope. For pCREB and pERK staining, confocal $2-\mu \mathrm{m}$ z-stack images were obtained using LAS AF software (Leica). Equal cutoff thresholds were applied to all slices. We quantified the number of pCREB-positive $\left(\mathrm{pCREB}^{+}\right)$and pERK-positive $\left(\mathrm{pERK}^{+}\right)$ cells using a $20 \times$ (for the mPFC and amygdala) or $40 \times$ (for the hippocampus) objective. For quantification of $\mathrm{pCREB}^{+}$and $\mathrm{pERK}^{+}$cells in the field of view within the mPFC and amygdala $(581 \times 581 \mu \mathrm{m}$; mPFC, bregma between 2.10 and $1.98 \mathrm{~mm}$; amygdala, bregma between -1.22 and $-1.34 \mathrm{~mm})$ and the hippocampus $(290 \times 290 \mu \mathrm{m}$; bregma between -1.46 and $-1.82 \mathrm{~mm}$ ) across at least two sections, computerized image analyses were performed as described previously (WinROOF version 5.6 software; Mitani Corporation).

\section{Surgery for drug microinfusion}

Surgery was performed as described previously (Frankland et al., 2006; Suzuki et al., 2008, 2011; Mamiya et al., 2009; Kim et al., 2011; Zhang et al., 2011; Nomoto et al., 2012; Fukushima et al., 2014; Ishikawa et al., 2016; Hasegawa et al., 2019). Under Nembutal anesthesia and using standard stereotaxic procedures, a stainless-steel guide cannula (22 gauge) was implanted into the $\mathrm{mPFC}$, dorsal hippocampus, or amygdala. Stereotaxic coordinates for the mPFC, dorsal hippocampus, or amygdala placement based on the brain atlas of Franklin and Paxinos (1997) were as follows: $\mathrm{mPFC}(2.7, \pm 0,-1.6 \mathrm{~mm})$, dorsal hippocampus $(-1.8, \pm$ $1.8,-1.9 \mathrm{~mm})$, and amygdala $(-1.3, \pm 3.3,-4.4 \mathrm{~mm})$. The mice were allowed to recover for at least one week after surgery. After this, they were handled for one week before the commencement of the IA task. Only mice with a cannulation tip within the boundaries of the amygdala, hippocampus, or mPFC were included in the data analysis. Cannulation tip placement is shown in Figure 8.

\section{Data analysis}

One-way ANOVA followed by post hoc Newman-Keuls test and twoway ANOVA followed by post hoc Bonferroni's comparisons were used to analyze the effects of group, drugs, reactivation and PR-LTM. A paired $t$ test was used to analyze the differences in crossover latency within each group between two sessions (reactivation vs PR-LTM). Un paired $t$ test was used to compare the levels of PCREB between two time points (5 vs $30 \mathrm{~min}$ ). All values in the text and figure legends are mean \pm SEM.

\section{Results}

\section{Characterization of memory phases after retrieval in the IA} task

The IA task allows us to discriminate the reconsolidation and extinction phases at the time point when a mouse enters a dark compartment from a light compartment (Fukushima et al., 2014). To understand the mechanism underlying the switch of memory phases from reconsolidation to extinction, we characterized the IA memory phases following memory retrieval by examining the effects of the inhibiting the protein synthesis that is required for the reconsolidation and extinction of IA memory (Fukushima et al., 2014). The mice were first placed in the light compartment. At $5 \mathrm{~s}$ after they entered the dark compartment, a brief electrical footshock was delivered (training). The mice were re-exposed to the light compartment at $24 \mathrm{~h}$ after the training (reactivation session; Fig. $1 A$ ) and their crossover latency to enter the dark compartment was assessed (Fig. 1B). The mice were returned into their home cages immediately after they entered into the dark compartment from the light compartment (0-min re-exposure to the dark compartment; reconsolidation phase) or stayed in the dark compartment for 1,3 , or $10 \mathrm{~min}$ without receiving a footshock (extinction phase; Fig. $1 C-E$ ). Immediately after the reactivation session, the mice received a systemic injection of VEH or the protein synthesis inhibitor ANI. At $48 \mathrm{~h}$ later, crossover latency was assessed PR-LTM.

Consistent with our previous study (Fukushima et al., 2014), re-exposure to the light compartment ( $0 \mathrm{~min}$ group) induced reconsolidation and enhancement of IA memory. A two-way ANOVA revealed significant effects of time $\left(F_{(1,24)}=10.433\right.$, $p=0.0036)$, drug $\left(F_{(1,24)}=23.197, p<0.0001\right)$ and time $\times$ drug 
A

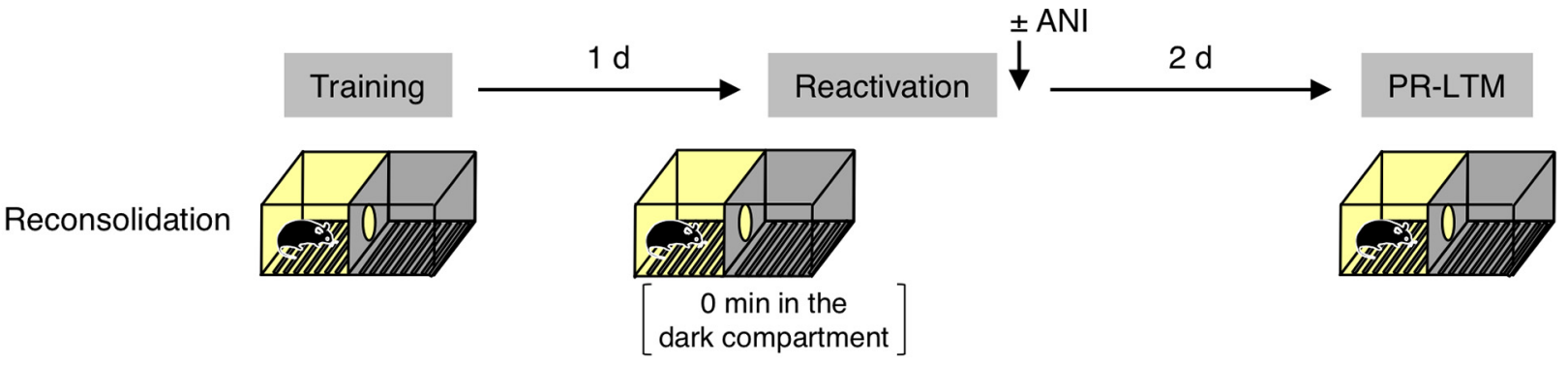

Extinction
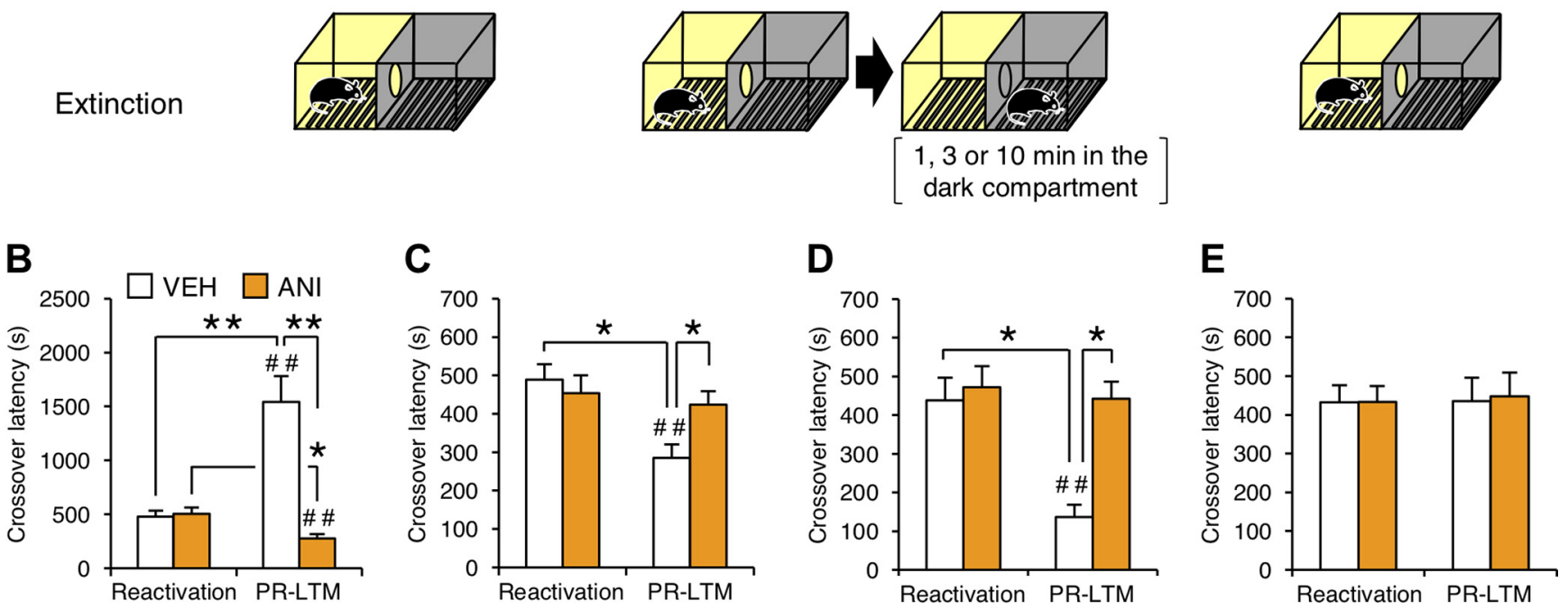

Figure 1. Memory phases after retrieval in the IA task. $\boldsymbol{A}$, Experimental design. $\boldsymbol{B}$, Re-exposure to the light compartment until the mouse entered the dark compartment. The VEH group showed enhancement of IA memory $(n=7)$. The ANI group showed disruption of reactivated IA memory $(n=7)$. $\boldsymbol{C}, \boldsymbol{D}$, Re-exposure to the dark compartment for $3 \mathrm{~min}(\boldsymbol{C})$ or $10 \mathrm{~min}(\boldsymbol{D})$ following re-exposure to the light compartment. The VEH groups showed the long-term extinction of IA memory, while ANI blocked this $(\boldsymbol{C}$, VEH, $\mathrm{n}=8, \mathrm{ANI}, \mathrm{n}=8$; $\boldsymbol{D}, \mathrm{VEH}, \mathrm{n}=10$, ANI, $\mathrm{n}=10$ ). $\boldsymbol{E}$, Re-exposure to the dark compartment for 1 min following re-exposure to the light compartment (VEH, $n=10$, ANI,

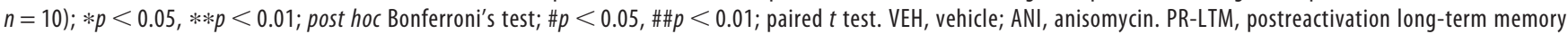
test. Error bars, SEM.

interaction $\left(F_{(1,24)}=25.022, p<0.0001\right.$; Fig. $\left.1 B\right)$. Post hoc Bonferroni's test and paired $t$ test revealed that the $\mathrm{VEH}$ and ANI groups, displayed significantly increased or decreased, respectively, crossover latency at PR-LTM compared with the reactivation session ( $p s<0.05 ; \mathrm{VEH}, t_{(6)}=-5.134, p=0.0021$, ANI, $t_{(6)}=4.804, p=0.003$; Fig. $1 B$ ). These observations indicate that IA memory retrieval in the light compartment enhanced the memory, while protein synthesis inhibition disrupted the retrieved memory, confirming the previous observation that IA memory retrieval enhances the memory through reconsolidation in protein synthesis-dependent manner.

In contrast, the re-exposure to the dark compartment induced long-term extinction [two-way ANOVA, time (Fig. $1 C, F_{(1,28)}=9.575, p=0.004$; Fig. $1 D, F_{(1,36)}=11.699$, $p=0.0016$ ), drug (Fig. $1 C, F_{(1,28)}=4.674, p=0.039$; Fig. $1 D$, $F_{(1,36)}=12.285, p=0.0012$ ), time $\times$ drug interaction (Fig. $1 C, F_{(1,28)}=7.916, p=0.009$; Fig. $1 D, F_{(1,36)}=7.915$, $p=0.0079$ )], as observed previously (Fukushima et al., 2014). The VEH groups that stayed in the dark compartment for 3 or 10 min showed significantly decreased crossover latency at PR-LTM compared with the reactivation session, whereas the ANI groups displayed comparable crossover latency at PR-LTM compared with the reactivation session and to the VEH groups (post hoc Bonferroni's test, $p$ s $<0.05$; paired $t$ test, Fig. $1 C, \mathrm{VEH}, t_{(7)}=4.976$, $p=0.0016$, ANI, $t_{(7)}=0.796, p>0.05$; Fig. $1 D, \mathrm{VEH}, t_{(9)}=$ $10.211, p<0.0001$, ANI, $\left.t_{(9)}=1.02, p>0.05\right)$. These observations indicate that the re-exposure to the dark compartment for 3 or 10 min extinguished IA memory and that inhibition of protein synthesis blocked long-term extinction. Thus, IA memory retrieval in the dark compartment extinguishes IA memory in a gene expression-dependent manner.

Importantly, the VEH group showed comparable crossover latency at PR-LTM compared with the reactivation session and to the ANI group when they stayed in the dark compartment for $1 \mathrm{~min}$ [two-way ANOVA, time $\left(F_{(1,36)}=\right.$ $0.03, p>0.05)$, drug $\left(F_{(1,36)}=0.019, p>0.05\right)$, time $\times$ drug interaction $\left(F_{(1,36)}=0.011, p>0.05\right)$; post hoc Bonferroni's test, $p$ s $>0.05$; paired $t$ test, VEH, $t_{(9)}=-0.091, p>0.05$, ANI, $t_{(9)}=-0.328, p>0.05$; Fig. $\left.1 E\right]$. These observations indicate that the VEH group showed neither enhancement nor extinction of IA memory and that the ANI group showed no disruption of IA memory. Therefore, re-exposure to the dark compartment for $1 \mathrm{~min}$ blocked both the enhancement and ANI-induced disruption of the reactivated IA memory, but not extinguished IA memory, suggesting that this 1-min re-exposure cancels the induction of reconsolidation, but is insufficient to extinguish IA memory.

In summary, these results indicated that re-exposure to the light compartment induces the reconsolidation phase, whereas longer re-exposure to the dark compartment ( 3 or $10 \mathrm{~min}$ ) induces the extinction phase. More importantly, staying for $1 \mathrm{~min}$ in the dark compartment induces the transition phase from reconsolidation to extinction, which, inhibits fear memory reconsolidation without inducing extinction. 
A
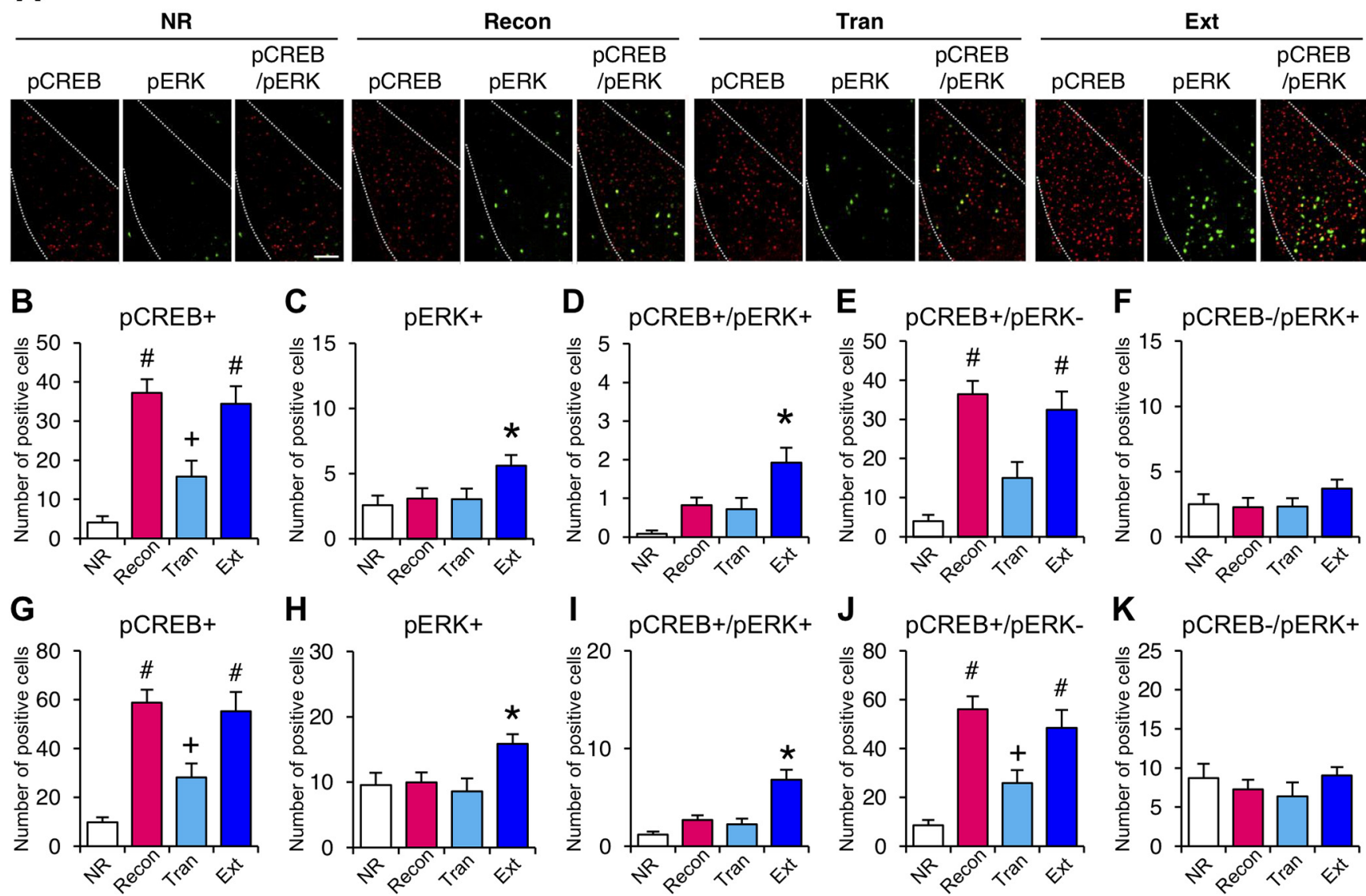

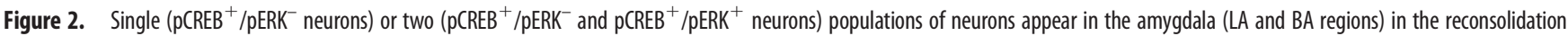
and extinction phases, respectively. $A$, Representative immunohistochemical staining of $\mathrm{pCREB}{ }^{+}, \mathrm{pERK}{ }^{+}$, and $\mathrm{pCREB}{ }^{+} / \mathrm{pERK}{ }^{+}$cells in the amygdala (LA and $\mathrm{BA}$ regions) from the indicated groups. Scale bar: $100 \mu \mathrm{m}$. pCREB ${ }^{+}(\boldsymbol{B}, \boldsymbol{G}), \mathrm{pERK}^{+}(\boldsymbol{C}, \boldsymbol{H}), \mathrm{pCREB}^{+} / \mathrm{pERK}^{+}(\boldsymbol{D}, \boldsymbol{I}), \mathrm{pCREB}^{+} / \mathrm{pERK}^{-}(\boldsymbol{E}, \boldsymbol{J})$, and pCREB ${ }^{-} / \mathrm{pERK}^{+}(\boldsymbol{F}, \boldsymbol{K})$ cells in the LA $(\boldsymbol{B}-\boldsymbol{F})$ and BA $(\boldsymbol{G}-\boldsymbol{K})$ regions of the amygdala (NR, $n=6$; Recon, $n=9$; Tran, $n=9$; Ext, $n=9$ ); \#p $<0.05$, compared with the NR and Tran groups $(\boldsymbol{B}, \boldsymbol{E}, \boldsymbol{G}, \boldsymbol{J}) ;{ }^{+} p<0.05$, compared with the NR group ( $\left.\boldsymbol{B}, \boldsymbol{G}, \boldsymbol{J}\right) ; * p<0.05$, compared with the other groups $(\boldsymbol{C}, \boldsymbol{D}, \boldsymbol{H}, \boldsymbol{I})$. BA, basolateral region of the amygdala; LA, lateral region of the amygdala; NR, non-reactivated group; Recon, reconsolidation group; Tran, transition group; Ext, extinction group. Error bars, SEM.

Molecular signatures of the reconsolidation, transition, and extinction phases in the amygdala, hippocampus, and mPFC after IA memory retrieval

Reconsolidation and extinction of contextual fear memory show increases in CREB phosphorylation at S133, a marker of gene expression activation required for reconsolidation and long-term extinction, but show distinct dynamics of CREB phosphorylation (Mamiya et al., 2009). Interestingly, recent studies have shown that there is no increase in the phosphorylation of ERK, an upstream regulator of CREB (Impey et al., 1998; Wu et al., 2001), in the basolateral region of the amygdala at the transition from reconsolidation to extinction of a cued fear memory, although this phosphorylation is increased in the basolateral region when a cued fear memory is reconsolidated and extinguished (Merlo et al., 2014, 2018). Another study indicated that hippocampal ERK is activated only when a contextual fear memory is extinguished, but not reconsolidated (Tronson et al., 2009). These findings suggest that reconsolidation, transition, and extinction phases show distinct molecular and cellular signatures. Therefore, we measured and compared the levels of PCREB and pERK in the reconsolidation, transition, and extinction phases using immunohistochemistry. We performed similar experimental schedules as in Figure $1 B, D, E$ using four experimental groups. The mice were re-exposed to the light compartment at $24 \mathrm{~h}$ after the training and then stayed in the dark compartment [reactivation: 0 min in the dark compartment, reconsolidation (Recon) group; $1 \mathrm{~min}$, transition (Tran) group; $10 \mathrm{~min}$, extinction (Ext) group]. Another group of mice were not returned to the light/dark compartment (non-reactivated, NR group). We counted pCREB-positive $\left(\mathrm{pCREB}^{+}\right)$neurons, pERK-positive $\left(\mathrm{pERK}^{+}\right)$neurons and double positive $\left(\mathrm{pCREB}^{+} / \mathrm{pERK}^{+}\right)$neurons in the amygdala, hippocampus, and $\mathrm{mPFC}$ at $30 \mathrm{~min}$ after the reactivation session.

\section{Amygdala (lateral region)}

CREB was activated in the extinction and reconsolidation phases, whereas ERK was activated only in the extinction phase (Fig. $2 A-C)$. A one-way ANOVA revealed a significant effect of group (Fig. $\left.2 B, F_{(3,29)}=14.85, p<0.0001\right)$. Similar to previous findings (Mamiya et al., 2009), post hoc Newman-Keuls test revealed that the Recon and Ext groups showed significantly more pCREB $^{+}$ neurons than the other groups $(p<0.05)$. These observations indicated that similar to the observations at the behavioral levels (Fig. 1), exposure to the dark compartment for $1 \mathrm{~min}$ (transition phase) cancels "turning-on" of CREB phosphorylation that would be increased in the reconsolidation phase. In contrast, significantly more $\mathrm{pERK}^{+}$neurons were observed in the Ext group than in the other groups, although there were much fewer $\mathrm{pERK}^{+}$neurons than $\mathrm{pCREB}^{+}$neurons in the Ext group $\left(F_{(3,29)}=3.793, p=\right.$ 0.0207; Fig. 2C). 
A

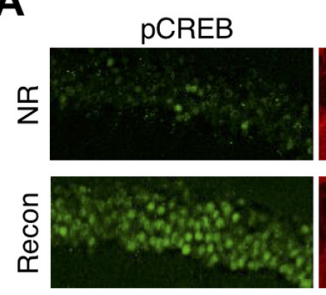

B

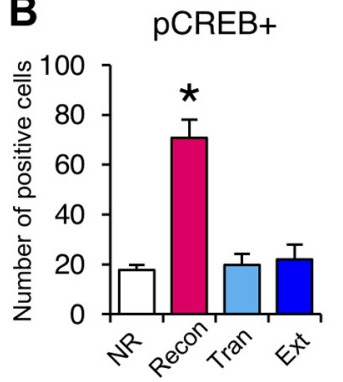

pERK

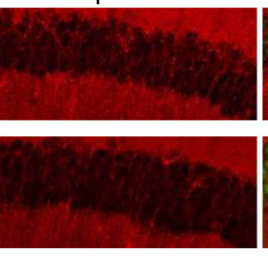

C

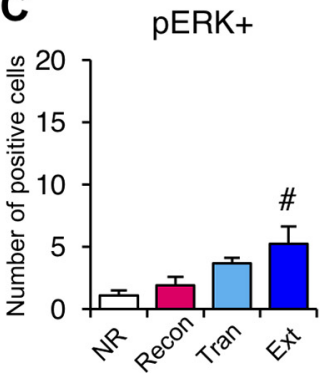

pCREB/pERK

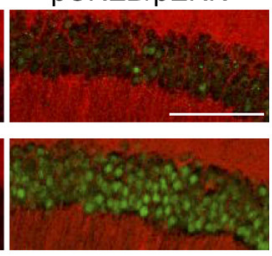

D

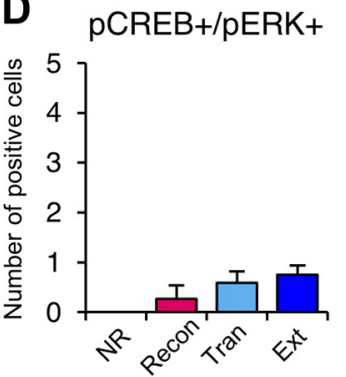

pCREB

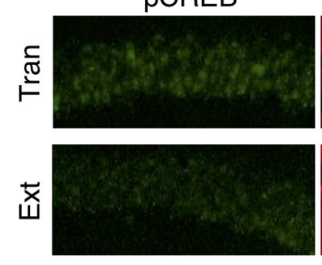

pERK

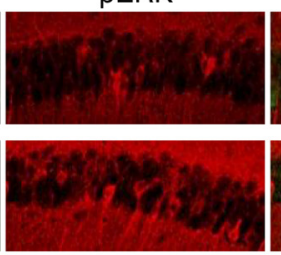

pCREB/pERK

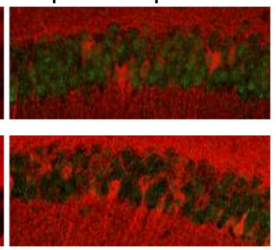

E

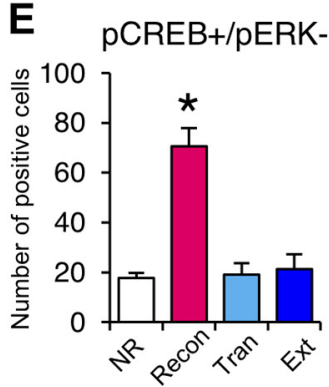

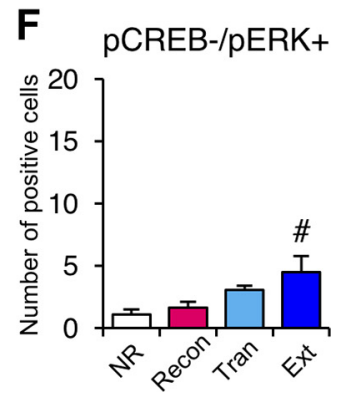

Figure 3. $p C R E B^{+} / p E R K^{-}$neurons or $p C R E B^{-} / p E R K^{+}$neurons appear in the CA1 region of the hippocampus in the reconsolidation and extinction phases, respectively. $A$, Representative immunohistochemical staining of pCREB ${ }^{+}, \mathrm{pERK}^{+}$, and pCREB ${ }^{+} / \mathrm{pERK}^{+}$cells in the CA1 region from the indicated groups. Scale bar: $100 \mu \mathrm{m} . \mathrm{pCREB}^{+}(\boldsymbol{B}), \mathrm{pERK}^{+}(\boldsymbol{C}), \mathrm{pCREB}^{+} / \mathrm{pERK}^{+}(\boldsymbol{D})$, $\mathrm{pCREB}^{+} / \mathrm{pERK}^{-}(\boldsymbol{E})$, and pCREB ${ }^{-} /$EERK $^{+}(\boldsymbol{F})$ cells in the CA1 region of the hippocampus (NR, $n=6$; Recon, $n=9 ;$ Tran, $n=9$; Ext, $n=9$ ); \#p $<0.05$, compared with the NR and Recon groups $(\boldsymbol{C}, \boldsymbol{F}) ; * p<0.05$, compared with the other groups $(\boldsymbol{B}, \boldsymbol{E})$. NR, non-reactivated group; Recon, reconsolidation group; Tran, transition group; Ext, extinction group. Error bars, SEM

Consistently, significantly more double positive neurons $\left(\mathrm{pCREB}^{+} / \mathrm{pERK}^{+}\right)$were observed in the Ext group $\left(F_{(3,29)}=\right.$ 6.698, $p=0.0014$; Fig. $2 D$ ), whereas significantly more pCREB $^{+}$/ $\mathrm{pERK}^{-}$(pCREB single positive) neurons were observed in the Recon and Ext groups $\left(F_{(3,29)}=13.689, p<0.0001\right.$; Fig. $\left.2 E\right)$. Thus, the reconsolidation phase showed only a single population of $\mathrm{pCREB}^{+} / \mathrm{pERK}^{-}$neurons. In contrast, the extinction phase showed two populations of $\mathrm{pCREB}^{+} / \mathrm{pERK}^{-}$and $\mathrm{pCREB}^{+}$/ $\mathrm{pERK}^{+}$neurons, indicating that ERK is activated only in a subset of $\mathrm{pCREB}^{+}$neurons. Importantly, similar results were observed in the basolateral region of the amygdala (Fig. $2 G, F_{(3,29)}=$ 13.042, $p<0.0001$; Fig. $2 H, F_{(3,29)}=3.824, p=0.0201$; Fig. $2 I$, $F_{(3,29)}=12.633, p<0.0001$; Fig. $\left.2 J, F_{(3,29)}=12.505, p<0.0001\right)$.

\section{Hippocampus (CA1 region)}

In contrast to the amygdala, CREB was activated only in the reconsolidation phase, whereas ERK was activated only in the extinction phase (Fig. $3 B, F_{(3,29)}=20.953, p<0.0001$; Fig. $3 C$, $\left.F_{(3,29)}=4.044, p=0.0162\right)$; significantly more $\mathrm{pCREB}^{+} / \mathrm{pERK}^{-}$ neurons and $\mathrm{pCREB}^{-} / \mathrm{pERK}^{+}$neurons were observed in the Recon and Ext groups, respectively, compared with the other groups (Fig. $3 E, F_{(3,29)}=20.609, p<0.0001$; Fig. $3 F, F_{(3,29)}=$ $3.647, p=0.024)$.

\section{mPFC (prelimbic region)}

Similar to the amygdala, CREB was activated in the extinction and reconsolidation phases, whereas ERK was activated only in the extinction phase; the Recon and Ext groups showed significantly more pCREB ${ }^{+}$neurons, while only the Ext group showed significantly more $\mathrm{pERK}^{+}$neurons, compared with the other groups (Fig. $4 B, F_{(3,29)}=9.804, p=0.0001$; Fig. $4 C, F_{(3,29)}=9.106$, $p=0.0002)$. Consistently, significantly more double positive neurons $\left(\mathrm{pCREB}^{+} / \mathrm{pERK}^{+}\right.$) were observed in the Ext group (Fig. $\left.4 D, F_{(3,29)}=7.735, p=0.0006\right)$, whereas significantly more $\mathrm{CREB}^{+} / \mathrm{pERK}^{-}$neurons were observed in the Recon and Ext groups (Fig. $4 E, F_{(3,29)}=8.869, p=0.0003$ ). In contrast to the results of the amygdala, significantly more $\mathrm{pCREB}^{-} / \mathrm{pERK}^{+}$ (pERK single positive) neurons appeared in the Ext group (Fig. $\left.4 F, F_{(3,29)}=3.948, p=0.0178\right)$. Importantly, similar results were observed in the infralimbic region of the mPFC (Fig. $4 G, F_{(3,29)}=$ 12.048, $p<0.0001$; Fig. $4 H, F_{(3,29)}=8.71, p=0.0003$; Fig. $4 I$, $F_{(3,29)}=10.879, p<0.0001$; Fig. $4 J, F_{(3,29)}=10.548, p<0.0001$; Fig. $\left.4 K, F_{(3,29)}=4.322, p=0.0123\right)$. These observations indicated that one $\left(\mathrm{pCREB}^{+} / \mathrm{pERK}^{-}\right.$neurons) or three $\left(\mathrm{pCREB}^{+} / \mathrm{pERK}^{-}\right.$, $\mathrm{pCREB}^{-} / \mathrm{pERK}^{+}$, and $\mathrm{pCREB}^{+} / \mathrm{pERK}^{+}$neurons) populations of neurons appear in the mPFC in the reconsolidation and extinction phases, respectively.

Collectively, our observations indicate that the reconsolidation, transition and extinction phases show distinct molecular signatures and that ERK is activated in the amygdala, hippocampus and mPFC only in the extinction phase. More importantly, exposure to the dark compartment for 1 min blocked the activation of CREB that would be observed unless the mice were reexposed to the dark compartment for a longer period of time, suggesting that the transition phase prevents the activation of CREB that would be observed in the reconsolidation phase. In line with the behavioral observations shown in Figure 1, these molecular and cellular observations showed that the transition memory phase appears after reconsolidation, but before extinction phases.

\section{Biphasic activation of ERK in the extinction phase}

ERK is an upstream activator of CREB and thereby, ERK activation is required for the consolidation and reconsolidation of fear memory (Schafe et al., 2000; Duvarci et al., 2005). However, inconsistently, no ERK activation was observed in the amygdala, hippocampus, or mPFC in the reconsolidation phase when pERK was measured at $30 \mathrm{~min}$ after the reactivation session (Figs. 2-4). Therefore, we examined the time courses of ERK and CREB phosphorylation. We performed a similar experiment as in Figures 2-4, except that pCREB and pERK levels were measured at 5,15 , and $30 \mathrm{~min}$ after the reactivation session (re-exposure to the dark compartment for 0,1 , or $10 \mathrm{~min}$; Fig. $5 \mathrm{~A}$ ). Consistent with the data shown in Figures 2-4, significant increases in $\mathrm{pCREB}^{+}$neurons were observed at $30 \mathrm{~min}$, but not at $5 \mathrm{~min}$, after the reactivation session in the Recon (amygdala, 
A
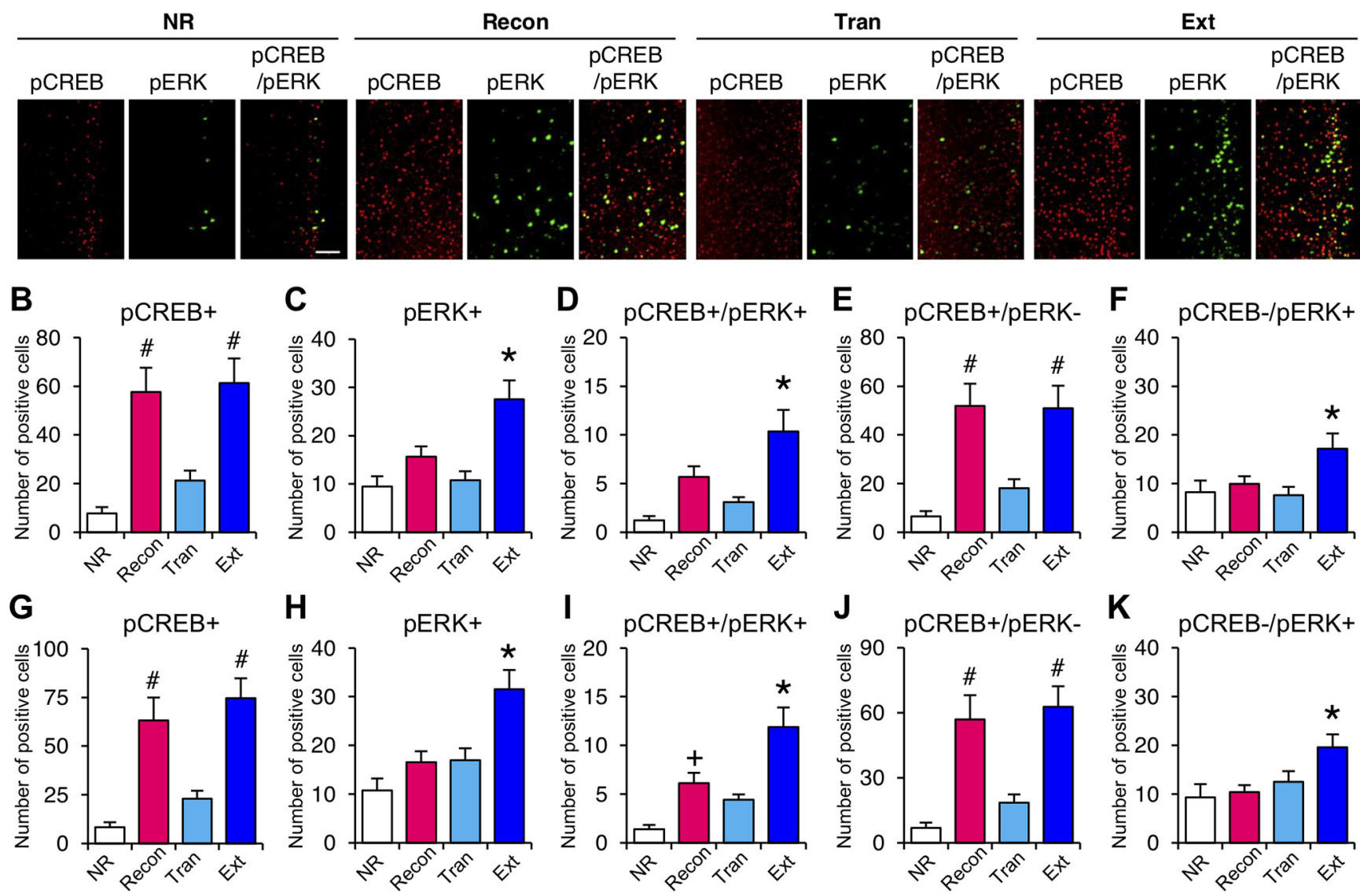

Figure 4. Single ( $\mathrm{pCREB}{ }^{+} / \mathrm{pERK}{ }^{-}$neurons) or three (pCREB ${ }^{+} / \mathrm{pERK}^{-}, \mathrm{pCREB}-/ \mathrm{pERK}^{+}$, and $\mathrm{pCREB}{ }^{+} / \mathrm{pERK}{ }^{+}$neurons) populations of neurons appear in the $\mathrm{mPFC}$ (PL and IL regions) in the reconsolidation and extinction phases, respectively. $A$, Representative immunohistochemical staining of $p C^{2}$ EEB ${ }^{+}, p$ ERK $^{+}$, and $p C R E B^{+} / p E R K^{+}$cells in the $\mathrm{mPFC}$ (PL and IL regions) from the indicated groups. Scale bar: $100 \mu \mathrm{m}$. pCREB ${ }^{+}(\boldsymbol{B}, \boldsymbol{G}), \mathrm{pERK}^{+}(\boldsymbol{C}, \boldsymbol{H}), \mathrm{pCREB}^{+} / \mathrm{pERK}^{+}(\boldsymbol{D}, \boldsymbol{I}), \mathrm{pCREB}^{+} / \mathrm{pERK}(\boldsymbol{E}, \boldsymbol{J})$, and pCREB ${ }^{-} / \mathrm{pERK}^{+}(\boldsymbol{F}, \boldsymbol{K})$ cells in the PL $(\boldsymbol{B}-\boldsymbol{F})$ and IL $(\boldsymbol{G}-\boldsymbol{K})$ regions of the $\mathrm{mPFC}(\mathrm{NR}, n=6$; Recon, $n=9$; Tran, $n=9$; Ext, $n=9) ; \# p<0.05$, compared with the NR and Tran groups $(\boldsymbol{B}, \boldsymbol{E}, \boldsymbol{G}, \boldsymbol{J}){ }^{+} p<0.05$, compared with the NR group $(\boldsymbol{l}) ; * p<0.05$, compared with the other groups $(\boldsymbol{C}, \boldsymbol{D}, \boldsymbol{F}, \boldsymbol{H}, \boldsymbol{I}, \boldsymbol{K})$. IL, infralimbic region of the $\mathrm{mPFC}$; PL, prelimbic region of the mPFC; NR, non-reactivated group; Recon, reconsolidation group; Tran, transition group; Ext, extinction group. Error bars, SEM.

mPFC and hippocampus) and Ext (amygdala and mPFC) groups, but not the Tran group (Fig. 5E, one-way ANOVA, amygdala, $5 \mathrm{~min}, F_{(3,23)}=0.346, p>0.05,30 \mathrm{~min}, F_{(3,23)}=$ 15.272, $p<0.0001 ; \mathrm{mPFC}, 5 \mathrm{~min}, F_{(3,23)}=1.169, p>0.05$, $30 \mathrm{~min}, F_{(3,23)}=32.346, p<0.0001$; hippocampus, $5 \mathrm{~min}$, $F_{(3,23)}=0.154, p>0.05,30 \mathrm{~min}, F_{(3,23)}=16.197, p<0.0001$; unpaired $t$ test, amygdala, reconsolidation, 5 vs $30 \mathrm{~min}, t_{(12)}=$ $-7.807, p<0.0001$, extinction, 5 vs $30 \mathrm{~min}, t_{(12)}=-5.405$, $p=0.0002$; mPFC, reconsolidation, 5 vs $30 \mathrm{~min}, t_{(12)}=-5.727$, $p<0.0001$, extinction, 5 vs $30 \mathrm{~min}, t_{(12)}=-4.188, p=0.0013$; hippocampal CA1 region, reconsolidation, 5 vs $30 \mathrm{~min}, t_{(12)}=$ $-2.339, p=0.0374)$.

Interestingly, significant increases in $\mathrm{pERK}^{+}$neurons were observed in the amygdala, mPFC and hippocampus of the Recon, Tran, and Ext groups at 5 min after the reactivation session compared with the NR group (Fig. $5 F$, amygdala, $F_{(3,23)}=$ $10.961, p=0.0001$; $\mathrm{mPFC}, F_{(3,23)}=7.525, p=0.0011$; hippocampus, $\left.F_{(3,23)}=6.924, p=0.0017\right)$. These observations indicated that ERK is activated immediately after the reactivation session in all memory phases. However, these increases in the number of $\mathrm{pERK}^{+}$neurons returned to basal levels (comparable with the $\mathrm{NR}$ group) at $15 \mathrm{~min}$ after the reactivation session (Fig. $5 F$, amygdala, $F_{(3,20)}=2.676, p>0.05 ; \mathrm{mPFC}, F_{(3,23)}=0.683$, $p>0.05$; hippocampus, $\left.F_{(3,20)}=0.74, p>0.05\right)$. Furthermore, consistent with the findings shown in Figures 2-4, significantly more $\mathrm{pERK}^{+}$neurons were observed in the amygdala, mPFC, and hippocampus at $30 \mathrm{~min}$ after the reactivation session only in the Ext group (Fig. $5 F$, amygdala, $F_{(3,23)}=6.616, p=0.022$; $\mathrm{mPFC}, F_{(3,23)}=8.012, p=0.0008$; hippocampus, $F_{(3,23)}=6.206$, $p=0.003)$. Thus, the reconsolidation and transition phases show transient activation of ERK only at the early time point (5 min), whereas the extinction phase shows biphasic activation of ERK at the early $(5 \mathrm{~min})$ and late $(30 \mathrm{~min})$ time points after the reactivation session. These observations indicated that the mechanisms for the regulation of ERK activation differ in the reconsolidation/ transition and extinction phases. Collectively, our observations demonstrated that the reconsolidation, transition, and extinction phases show distinct molecular signatures.

\section{Roles of ERK activation in reconsolidation and extinction phases of IA memory}

The reconsolidation/transition and extinction phases showed monophasic and biphasic ERK activation, respectively. We next investigated and compared the roles of early $(5 \mathrm{~min})$ and late ( $30 \mathrm{~min}$ ) ERK activation in the $\mathrm{mPFC}$ in the reconsolidation and extinction phases by examining the effects of inhibiting ERK (Fig. 6).

We performed reconsolidation experiments similar to those in Figure $1 B$, except that the mice received a microinfusion of the MEK inhibitor (U0126) into the mPFC immediately 
A
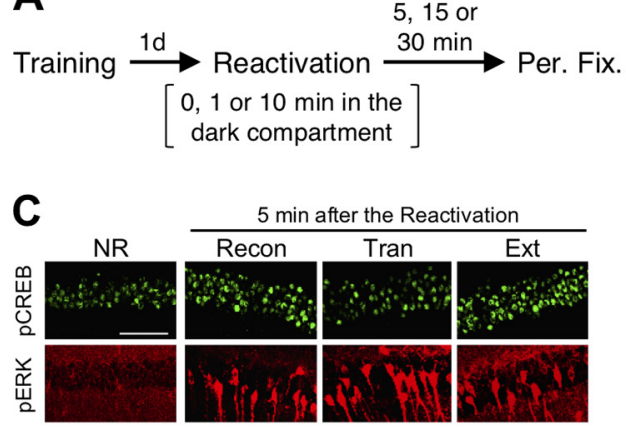

15 min after the Reactivation

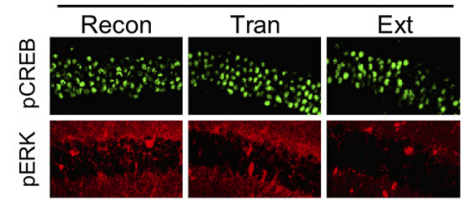

$30 \mathrm{~min}$ after the Reactivation

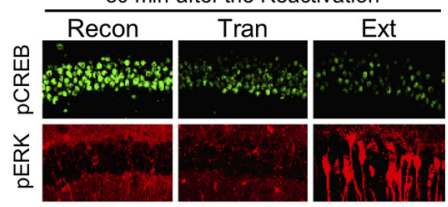

B

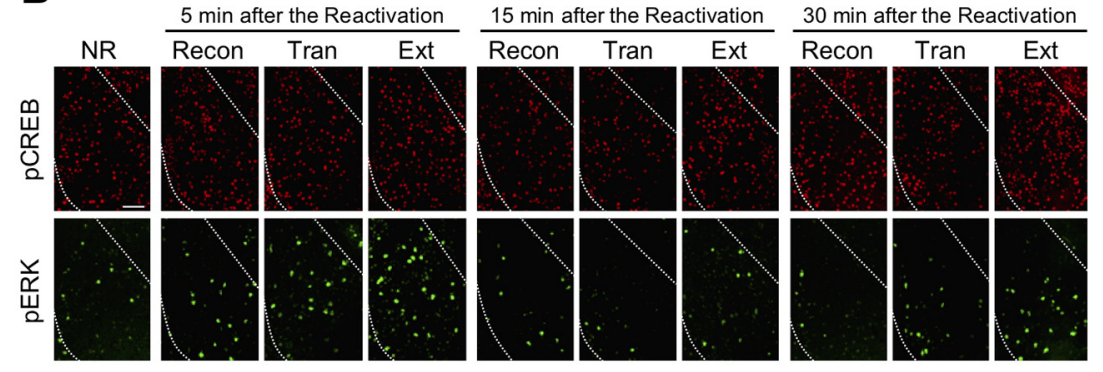

D

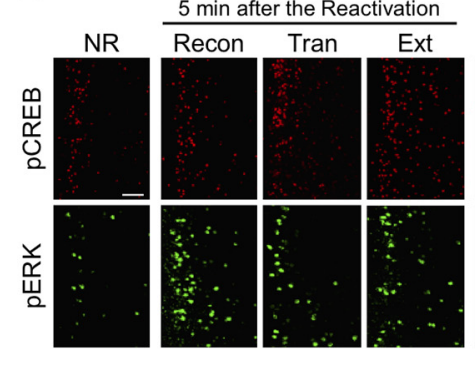

15 min after the Reactivation

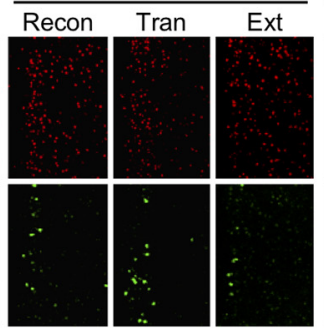

30 min after the Reactivation
Recon Tran Ext

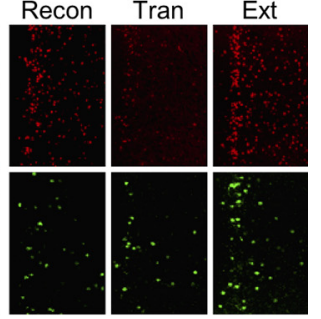

\section{E $\square$ Reconsolidation $\square$ Transition $\square$ Extinction}
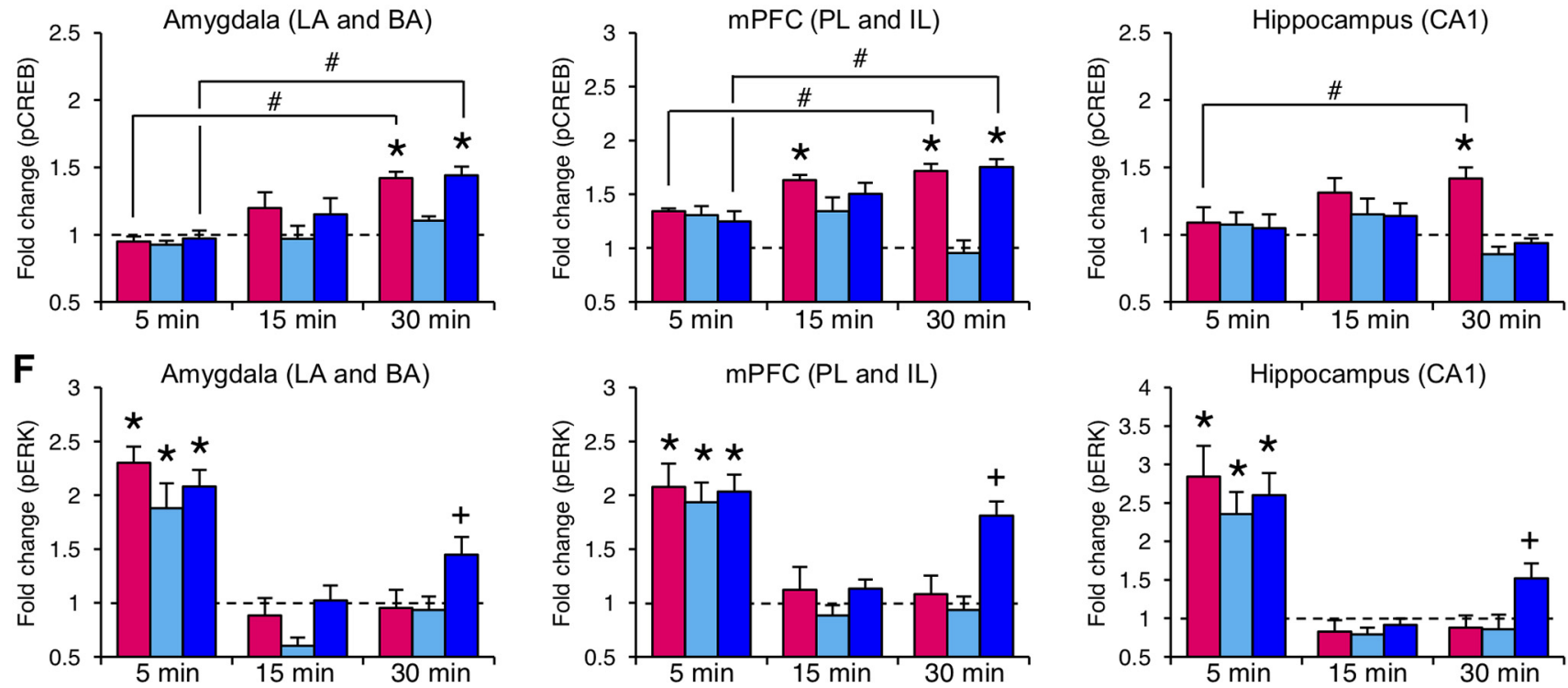

Figure 5. Time course analysis of the phosphorylation levels of CREB and ERK following the reactivation session. $\boldsymbol{A}$, Experimental design. $\boldsymbol{B}-\boldsymbol{D}$, Representative immunohistochemical staining of pCREB ${ }^{+}$and pERK ${ }^{+}$cells in the amygdala $(\boldsymbol{B})$, CA1 region of the hippocampus $(\boldsymbol{C})$, and $\mathrm{mPFC}(\boldsymbol{D})$ of the indicated groups. Scale bar: $100 \mu \mathrm{m} . \boldsymbol{E}, \mathrm{pCREB}$ levels in the amygdala, mPFC, and CA1 region of the hippocampus after reactivation ( $n=6-7$ for each group). $F$, pERK levels in the amygdala, mPFC, and CA1 region of the hippocampus after reactivation ( $n=6-7$ for each group). The dashed line represents the NR group; $* p<0.05$, compared with the NR group; $+p<0.05$, compared with the other groups at 30 min after the reactivation session; post hoc Newman-Keuls test; $\# p<0.05$; unpaired $t$ test. LA, lateral region of the amygdala; $\mathrm{BA}$, basolateral region of the amygdala; PL, prelimbic region of the $\mathrm{mPFC}$; $\mathrm{LL}$, infralimbic region of the mPFC; NR, non-reactivated group; Recon, reconsolidation group; Tran, transition group; Ext, extinction group. Error bars, SEM.

(Fig. $6 \mathrm{~A}$ ) or at $30 \mathrm{~min}$ (Fig. $6 B$ ) after the reactivation session to block ERK activation at the early and late time points, respectively. Microinfusion immediately, but not at $30 \mathrm{~min}$, after the reactivation session blocked the enhancement of IA memory [two-way ANOVA, time (Fig. $6 A, F_{(1,38)}=20.268, p<0.0001$; Fig. $6 B, F_{(1,36)}=26.497, p<0.0001$ ), drug (Fig. $6 A, F_{(1,38)}=$ 17.003, $p=0.002$; Fig. $\left.6 B, F_{(1,36)}=0.069, p>0.05\right)$, time $\times$ drug interaction (Fig. $6 A, F_{(1,38)}=18.118, p=0.0001$; Fig. $6 B, F_{(1,36)}=$ $0.027, p>0.05)]$. The groups that received U0126 immediately or at $30 \mathrm{~min}$ after the reactivation session showed comparable and significantly longer crossover latencies, respectively, at PRLTM compared with the reactivation session (post hoc Bonferroni's test, $p$ s $<0.05$; paired $t$ test, Fig. $6 A$, VEH, $t_{(9)}=-5.104, p=0.0006$, U0126, $t_{(10)}=-0.364, p>0.05$; Fig. $6 B$, VEH, $t_{(9)}=-4.499$, $\left.p=0.0015, \mathrm{U} 0126, t_{(9)}=-4.361, p=0.0018\right)$. These observations suggested that ERK activation in the mPFC in the early reconsolidation phase is required for the reconsolidation/enhancement of IA memory. 
A
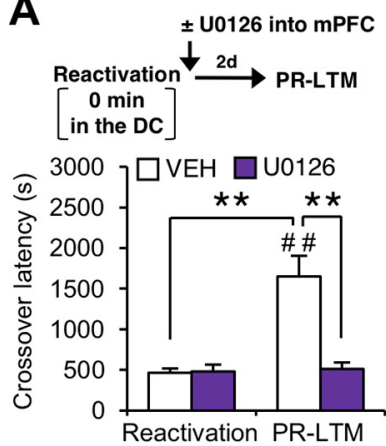

$\mathbf{E}$
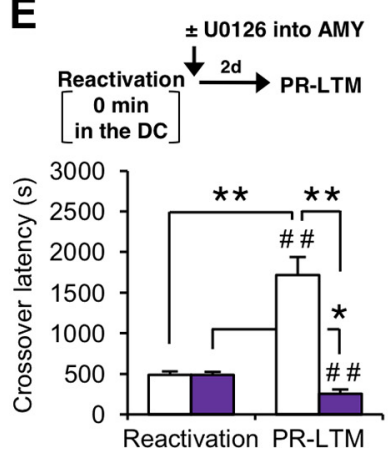

B
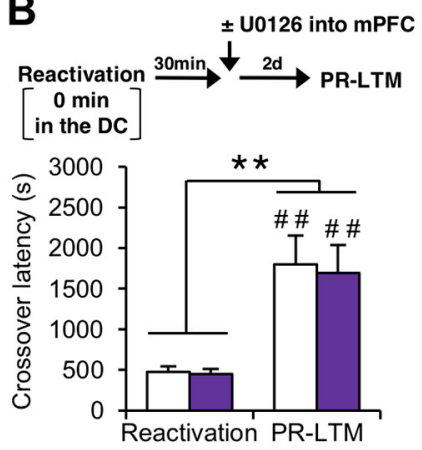

$\mathbf{F}$
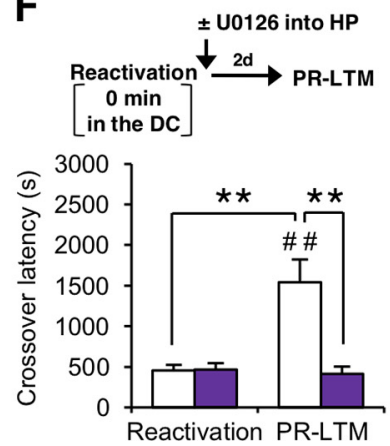
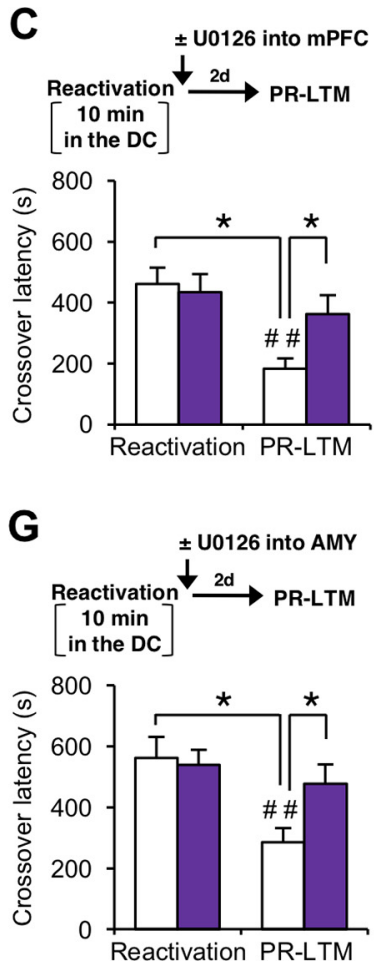
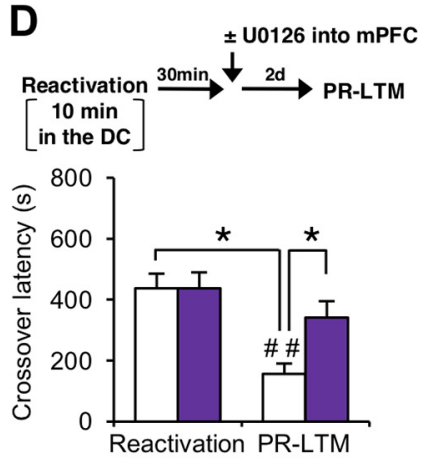

H
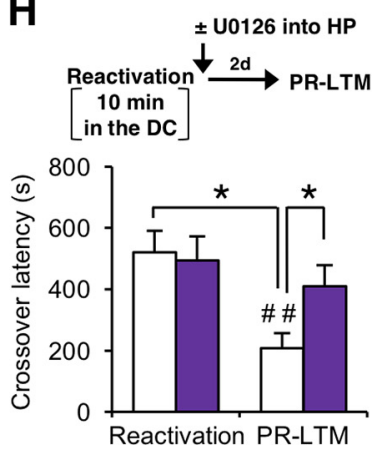

Figure 6. Inhibition of ERK in the mPFC, amygdala, or hippocampus blocks the reconsolidation/enhancement and long-term extinction of IA memory. $\boldsymbol{A}, \boldsymbol{B}$, Effects of U0126 microinfusion into the mPFC immediately $(\boldsymbol{A})$ or at $30 \mathrm{~min}(\boldsymbol{B})$ after the reactivation session (re-exposure to the dark compartment for 0 min; $\boldsymbol{A}, \mathrm{VEH}, n=10, \mathrm{U} 0126, n=11 ; \boldsymbol{B}, \mathrm{VEH}, n=10, \mathrm{U} 0126, n=10$ ). $\boldsymbol{C}, \boldsymbol{D}$, Effects of U0126 microinfusion into the $\mathrm{mPFC}$ immediately $(\boldsymbol{C})$ or at $30 \mathrm{~min}(\boldsymbol{D})$ after the reactivation session (re-exposure to the dark compartment for $10 \mathrm{~min}$; $\boldsymbol{C}$, VEH, $n=10$, U0126, $n=10 ; \boldsymbol{D}$, VEH, $n=10, \mathrm{U} 0126, n=10) . \boldsymbol{E}, \boldsymbol{F}$, Effects of U0126 microinfusion into the amygdala $(\boldsymbol{E})$ or hippocampus $(\boldsymbol{F})$ immediately after the reactivation session (re-exposure to the dark compartment for 0 min; $\boldsymbol{E}$, VEH, $n=10$, U0126, $n=10 ; \boldsymbol{F}$, VEH, $n=10$, U0126, $n=10)$. $\boldsymbol{G}, \boldsymbol{H}$, Effects of U0126 microinfusion into the amygdala ( $\boldsymbol{G})$ or hippocampus $(\boldsymbol{H})$ immediately after the reactivation session (re-exposure to the dark compartment for $10 \mathrm{~min} ; \boldsymbol{G}, \mathrm{VEH}, n=9$, U0126, $n=9 ; \boldsymbol{H}, \mathrm{VEH}, n=10, \mathrm{U} 0126, n=10$ ); $* p<0.05$, $* * p<0.01$; post hoc Bonferroni's test; $\# p<0.05$, \#\#p<0.01; paired $t$ test. AMY, amygdala; HP, hippocampus; VEH, vehicle; DC, dark compartment. PR-LTM, postreactivation long-term memory test. Error bars, SEM.

We next performed extinction experiments similar to those in Figure $6 A, B$. Microinfusion of U0126 into the mPFC immediately or at $30 \mathrm{~min}$ after the reactivation session impaired the long-term extinction of IA memory [time (Fig. 6C, $F_{(1,36)}=$ 9.534, $p=0.004$; Fig. $6 D, F_{(1,36)}=13.757, p=0.0007$ ), drug (Fig. $6 C, F_{(1,36)}=4.231, p=0.047$; Fig. $\left.6 D, F_{(1,36)}=6.153, p=0.0179\right)$, time $\times$ drug interaction (Fig. $6 C, F_{(1,36)}=6.717, p=0.014$; Fig. $\left.\left.6 D, F_{(1,36)}=6.142, p=0.018\right)\right]$. Both U0126 groups showed comparable crossover latency at PR-LTM, whereas the VEH groups showed significantly decreased crossover latency compared with reactivation session (post hoc Bonferroni's test, $p s<0.05$; paired $t$ test, Fig. $6 C, \mathrm{VEH}, t_{(9)}=11.598, p<0.0001, \mathrm{U} 0126, t_{(9)}=1.632$, $p>0.05$; Fig. $6 D, \mathrm{VEH}, t_{(9)}=7.885, p<0.0001, \mathrm{U} 0126, t_{(9)}=$ $2.059, p>0.05)$. These observations suggested that ERK activations in the early and late extinction phases is required for the long-term extinction of IA memory. It is important to note that similar results were observed when U0126 was microinfused into the amygdala or hippocampus in experiments of reconsolidation [time (Fig. $6 E, F_{(1,36)}=18.753, p=0.0001$; Fig. $6 F, F_{(1,36)}=10.64$, $p=0.0024$ ), drug (Fig. $6 E, F_{(1,36)}=40.41 \mathrm{~F} 1, p<0.0001$; Fig. $6 F$, $F_{(1,36)}=12.47, p=0.0012$ ), time $\times$ drug interaction (Fig. $6 E$, $F_{(1,36)}=40.477, p<0.0001$; Fig. $\left.6 F, F_{(1,36)}=12.789, p=0.001\right)$; post hoc Bonferroni's test, $p s<0.05$; paired $t$ test, Fig. $6 E, \mathrm{VEH}$, $t_{(9)}=-5.826, p=0.0003$, U0126, $t_{(9)}=4.534, p=0.0014$; Fig. $6 F$, $\left.\mathrm{VEH}, t_{(9)}=-4.463, p=0.0016, \mathrm{U} 0126, t_{(9)}=0.568, p>0.05\right]$ and extinction [time (Fig. $6 G, F_{(1,32)}=8.475, p=0.0065$; Fig. $6 H$, $F_{(1,36)}=10.42, p=0.0027$ ), drug (Fig. $6 G, F_{(1,32)}=4.993$, $p=0.0398$; Fig. $\left.6 H, F_{(1,36)}=4.28, p=0.0485\right)$, time $\times$ drug interaction (Fig. $6 G, F_{(1,32)}=4.51, p=0.0415$; Fig. $6 H, F_{(1,36)}=4.27$, $p=0.046$ ); post hoc Bonferroni's test, $p s<0.05$; paired $t$ test, Fig. $6 G, \mathrm{VEH}, t_{(8)}=7.027, p=0.0001, \mathrm{U} 0126, t_{(8)}=0.638, p>0.05$; Fig. $6 H, \mathrm{VEH}, t_{(9)}=7.091, p<0.0001, \mathrm{U} 0126, t_{(9)}=2.183$, $p>0.05]$. Thus, our observations indicated that monophasic and biphasic ERK activation is required for the reconsolidation and extinction, respectively, of IA memory.

\section{Roles of ERK activation in the transition phase of IA memory}

Interestingly, ERK activation was observed in the mPFC, amygdala, and hippocampus in the early transition phase (at $5 \mathrm{~min}$ after the reactivation session; Fig. 5); therefore, it is possible that it is required for the transition from the reconsolidation to extinction phase. We performed similar transition experiments as in Figure 6, by examining the effects of U0126 microinfusion into the mPFC, amygdala, or hippocampus immediately after re-exposure to the dark compartment for $1 \mathrm{~min}$ (Fig. $7 A-C$ ). A twoway ANOVA revealed significant effects of time (Fig. $7 A$, $F_{(1,42)}=7.748, p=0.008$; Fig. $7 B, F_{(1,38)}=8.124, p=0.007$; Fig. $7 C, F_{(1,40)}=5.242, p=0.0274$ ), drug (Fig. $7 A, F_{(1,42)}=8.174$, $p=0.0066$; Fig. $7 B, F_{(1,38)}=7.208, p=0.0011$; Fig. $7 C, F_{(1,40)}=$ 5.427, $p=0.025)$ and time $\times$ drug interaction (Fig. $7 A, F_{(1,42)}=$ 7.092, $p=0.0109$; Fig. $7 B, F_{(1,38)}=7.017, p=0.0117$; Fig. $7 C$, $\left.F_{(1,40)}=5.428, p=0.0249\right)$. Consistent with the data shown in Figure 1, the VEH groups demonstrated comparable crossover latency at PR-LTM compared with the reactivation session. Interestingly, in contrast to the results of protein synthesis inhibition (Fig. 1E), the mice that received a microinfusion of U0126 into the $\mathrm{mPFC}$, amygdala, or hippocampus showed significantly 
A
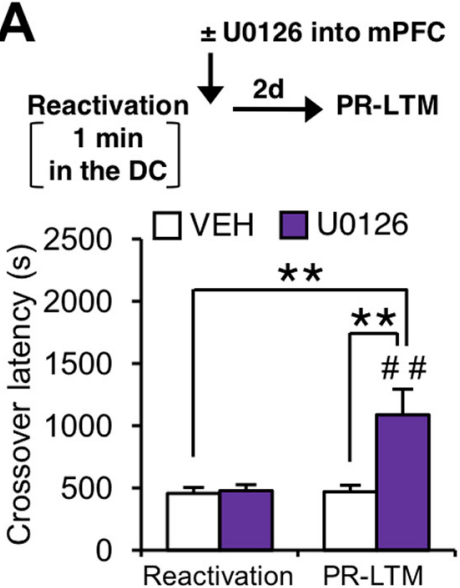

D
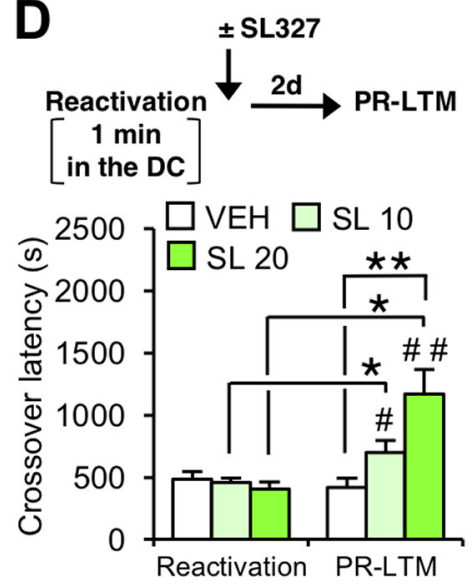

B
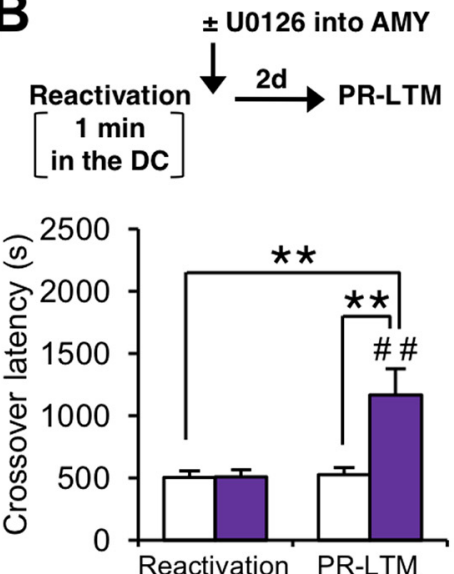

$\mathbf{E}$
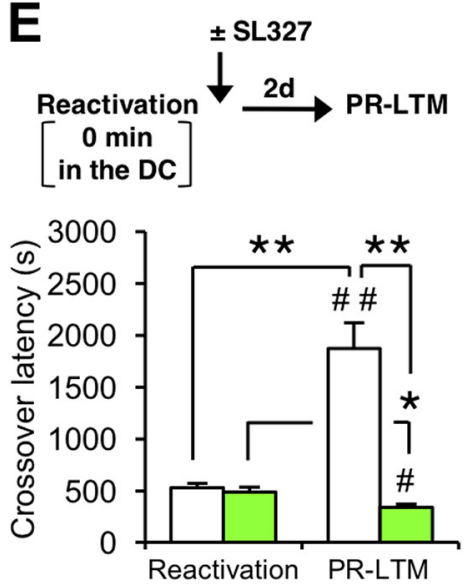
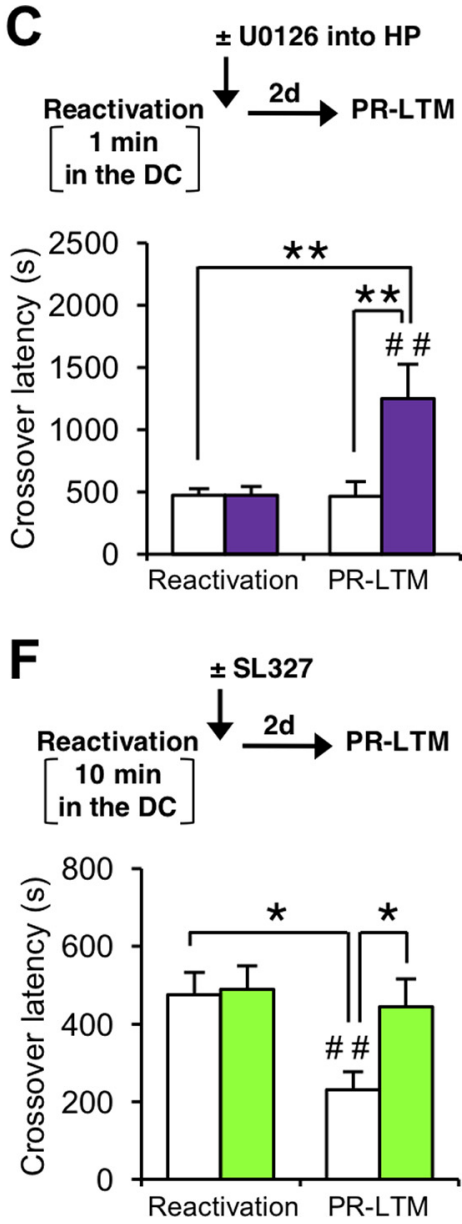

Figure 7. Inhibition of ERK in the $\mathrm{mPFC}$, amygdala, or hippocampus disinhibits reconsolidation/enhancement of IA memory. $\boldsymbol{A}-\boldsymbol{C}$, Effects of U0126 microinfusion into the mPFC $(\boldsymbol{A})$, AMY $(\boldsymbol{B})$, or HP $(\boldsymbol{C})$ immediately after the reactivation session (re-exposure to the dark compartment for $1 \mathrm{~min} ; \boldsymbol{A}, \mathrm{VEH}, n=12, \mathrm{U} 0126, n=11 ; \boldsymbol{B}, \mathrm{VEH}, n=10, \mathrm{U} 0126, n=11 ; \boldsymbol{C}, \mathrm{VEH}, n=10$, U0126, $n=12)$. D $-\boldsymbol{F}$, Systemic injection of a high dose of SL327 (20 mg/kg) blocked the transition $(\boldsymbol{D})$, reconsolidation $(\boldsymbol{E})$, and extinction $(\boldsymbol{F})$ of IA memory $(\boldsymbol{D}, \mathrm{VEH}, n=10$, SL327 $10 \mathrm{mg} / \mathrm{kg}$, $n=10$, SL327 $20 \mathrm{mg} / \mathrm{kg}, n=11 ; \boldsymbol{E}$, VEH, $n=10$, SL327 $20 \mathrm{mg} / \mathrm{kg}, n=10 ; \boldsymbol{F}$, VEH, $n=10$, SL327 $20 \mathrm{mg} / \mathrm{kg}, n=10) ; * p<0.05, * * p<0.01 ;$ post hoc Bonferroni's test; \#p<0.05, $\# \# p<0.01$; paired $t$ test. AMY, amygdala; HP, hippocampus; VEH, vehicle; SL 10, SL327 $10 \mathrm{mg} / \mathrm{kg}$; SL 20, SL327 20 mg/kg; DC, dark compartment. PR-LTM, postreactivation long-term memory test. Error bars, SEM.

longer crossover latency at PR-LTM compared with the reactivation session (post hoc Bonferroni's test, ps $<0.05$; paired $t$ test, Fig. $7 A, \mathrm{VEH}, t_{(11)}=-0.252, p>0.05, \mathrm{U} 0126, t_{(10)}=-3.22$, $p=0.0092$; Fig. $7 B, \mathrm{VEH}, t_{(9)}=-0.531, p>0.05$, U0126, $t_{(10)}=$ $-3.94, p=0.0028$; Fig. $7 C, \mathrm{VEH}, t_{(9)}=0.068, p>0.05$, U0126, $\left.t_{(11)}=-3.279, p=0.0073\right)$, indicating that the inhibition of ERK enhanced IA memory. These results suggest that ERK inhibition disinhibited IA memory enhancement in the transition phase. It is important to note that the systemic injection of a MEK inhibitor (SL327) in the transition phase also prevented the inhibition of IA memory enhancement in a dose-dependent manner [Fig. $7 D$, time $\left(10 \mathrm{mg} / \mathrm{kg}, F_{(1,36)}=2.3, p>0.05 ; 20 \mathrm{mg} / \mathrm{kg}, F_{(1,38)}=\right.$ 9.046, $p=0.0047)$, drug $\left(10 \mathrm{mg} / \mathrm{kg}, F_{(1,36)}=4.554, p=0.0397\right.$; $\left.20 \mathrm{mg} / \mathrm{kg}, F_{(1,38)}=8.369, p=0.0063\right)$, time $\times$ drug interaction $\left(10 \mathrm{mg} / \mathrm{kg}, F_{(1,36)}=6.574, p=0.0147 ; 20 \mathrm{mg} / \mathrm{kg}, F_{(1,38)}=12.734\right.$, $p=0.001)$; post hoc Bonferroni's test, $p$ s $<0.05$; paired $t$ test, $\mathrm{VEH}, t_{(9)}=1.522, p>0.05,10 \mathrm{mg} / \mathrm{kg}, t_{(9)}=-3.205, p=0.0107$, $\left.20 \mathrm{mg} / \mathrm{kg}, t_{(10)}=-4.293, p=0.0016\right]$, whereas MEK inhibition in the reconsolidation and extinction phases blocked reconsolidation and extinction, respectively, of IA memory [time (Fig. 7E, $F_{(1,36)}=21.37, p<0.0001$; Fig. $\left.7 F, F_{(1,36)}=6.309, p=0.0166\right)$, drug $\left(7 E, F_{(1,36)}=37.27, p<0.0001\right.$; Fig. $7 F, F_{(1,36)}=5.36$, $p=0.0264$ ), time $\times$ drug interaction (Fig. $7 E, F_{(1,36)}=33.701$, $p<0.0001$; Fig. $\left.7 F, F_{(1,36)}=4.379, p=0.0435\right)$; post hoc Bonferroni's test, Fig. $7 E, F, p s<0.05$; paired $t$ test, Fig. $7 E, \mathrm{VEH}$, $t_{(9)}=-6.005, p=0.0002$, SL327, $t_{(9)}=3.158, p=0.0116$; Fig. $7 F$, $\mathrm{VEH}, t_{(9)}=12.236, p<0.0001$, SL327, $\left.t_{(9)}=0.549, p>0.05\right]$. Collectively, these observations suggested that the ERK activation observed in the transition phase is required for inhibition of the reconsolidation of IA memory and that this transition process contributes to the switch of memory phases by preventing reconsolidation via the activation of the ERK-signaling pathway.

\section{Discussion}

In this study, we investigated the mechanisms for memory transition from the reconsolidation to extinction phases after the retrieval of IA memory. We first characterized the behavioral signatures of IA memory phases after retrieval. Consistent with our previous study (Fukushima et al., 2014), IA memory retrieval induced reconsolidation and extinction by re-exposure to the light ( $0 \mathrm{~min}$ in the dark compartment) and dark ( 3 or $10 \mathrm{~min}$ ) compartments, respectively. Interestingly, IA memory was neither enhanced nor extinguished and showed resistance to the inhibition of protein synthesis when the mice were re-exposed to the dark compartment for only $1 \mathrm{~min}$. Therefore, these 

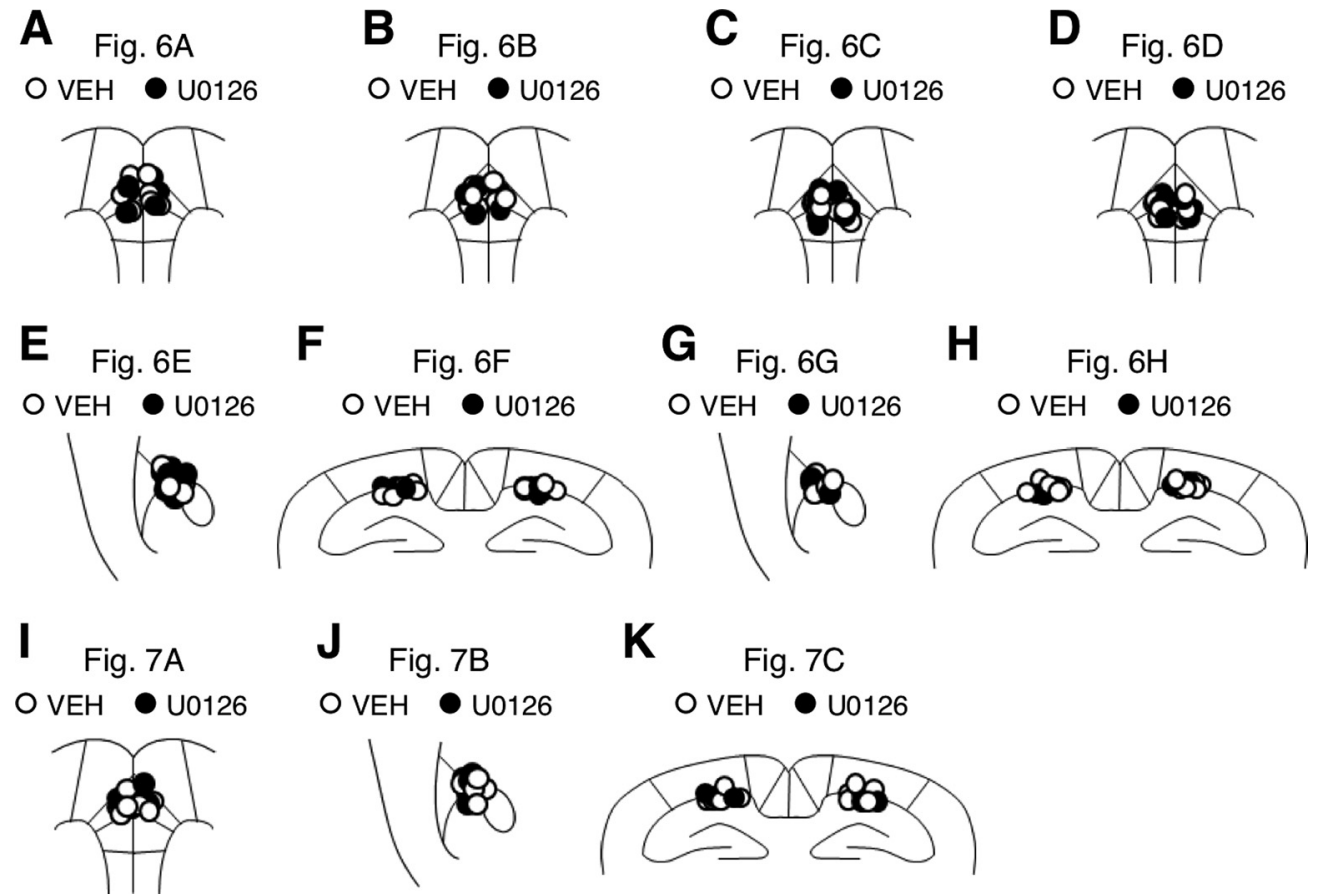

Figure 8. Cannula tip placement in the amygdala, hippocampus, and mPFC. $\boldsymbol{A}-\boldsymbol{K}$, Cannula tip placement from mice infused with each drug shown in Figures $6 A(\boldsymbol{A}), B(\boldsymbol{B}), C(\boldsymbol{C}), D(\boldsymbol{D}), E$ $(\boldsymbol{E}), F(\boldsymbol{F}), G(\boldsymbol{G}), H(\boldsymbol{H})$ and $7 A(\boldsymbol{I}), B(\boldsymbol{J}), \boldsymbol{C}(\boldsymbol{K})$. Schematic drawing of coronal sections from all microinfused animals (amygdala, $1.34 \mathrm{~mm}$ posterior to bregma; hippocampus, $1.94 \mathrm{~mm}$ posterior to bregma; $\mathrm{mPFC}, 1.94 \mathrm{~mm}$ anterior to bregma). Only mice with needle tips within the boundaries of the amygdala, hippocampus, or mPFC were included in the data analysis. VEH: vehicle.

observations suggest that 1 -min re-exposure to the dark compartment cancels the induction of reconsolidation, but is insufficient to extinguish IA memory. Furthermore, we found that ERK was activated in the amygdala, hippocampus, and $\mathrm{MPFC}$ at an early time point $(5 \mathrm{~min}$ ) after re-exposure to the dark compartment for 0,1 , or $10 \mathrm{~min}$. Consistently, the inhibition of ERK in these brain regions blocked the reconsolidation/enhancement and extinction of IA memory. Most importantly, ERK inhibition in the amygdala, hippocampus, and $\mathrm{mPFC}$ following 1-min reexposure to the dark compartment disinhibited the reconsolidation-mediated enhancement of IA memory, suggesting that ERK activation following brief ( $1 \mathrm{~min}$ ) re-exposures to the dark compartment is required for the inhibition of IA memory reconsolidation. Conversely, 1-min re-exposure to the dark compartment was insufficient to extinguish IA memory, although extended reexposure to the dark compartment ( 3 or $10 \mathrm{~min}$ ) extinguished this memory. Therefore, our results suggest that 1-min re-exposure to the dark compartment induces a memory transition process that cancels reconsolidation/enhancement, but does not initiate extinction learning. Collectively, we suggest that the memory transition process contributes to the switch of memory phases from reconsolidation to extinction through ERK-mediated prevention of reconsolidation.

Similar to our current observations, a recent study using auditory fear conditioning showed that single (1) or prolonged (10) CS presentations induce memory reconsolidation and extinction, respectively, through an increase of pERK levels in the basolateral region of the amygdala. In contrast, intermediate (4-7) CS presentations do not change pERK levels in the basolateral region of the amygdala. Importantly, ERK inhibition at the intermediate CS presentations did not affect fear memory. This study suggested that there is a transition of memory phase from reconsolidation to extinction after fear memory retrieval (Merlo et al., 2018). In the present study, we extended this finding and suggested that the transition phase actively switches memory phases from reconsolidation to extinction through the activation of the ERK signal transduction pathway. In contrast to previous finding (Merlo et al., 2018), we found that the transition phase involves ERK phosphorylation in the amygdala, hippocampus, and $\mathrm{mPFC}$. These discrepancies may be because of the difference of time points examining ERK phosphorylation; the previous study measured pERK levels at $\sim 12 \mathrm{~min}$ after CS presentation (Merlo et al., 2018), while our study showed that increased pERK levels returned to the basal level at around this time point (15 min after the re-exposure). Additionally, it is important to note that the IA task enables the observation of the enhancement of IA memory through reconsolidation, thereby leading to our finding that the inhibition of ERK at the transition phase disinhibits the enhancement of IA memory.

Previous studies have shown that ERK phosphorylation is increased in the basolateral region of the amygdala at 20-60 min following extinction learning of cued fear memory (Herry et al., 2006; Merlo et al., 2014, 2018), whereas the hippocampus shows this activation at $1 \mathrm{~h}$ following the extinction learning of contextual fear memory (Fischer et al., 2007; Tronson et al., 2009). In the present study, we obtained similar observations that pERK is increased at $30 \mathrm{~min}$ after the reactivation session in the extinction phase. These findings suggest that ERK phosphorylation is a common molecular signature of the late extinction phase (20$60 \mathrm{~min})$.

Furthermore, we observed that ERK activation occurs biphasically at early and late time points ( 5 and $30 \mathrm{~min}$ ) after the reactivation session in the extinction phase, whereas this activation occurs monophasically at the early time point in the reconsolidation phase (Fig. 5). Consistently, inhibiting ERK in brain regions at these time points of the reconsolidation and extinction phases blocked reconsolidation/enhancement and long-term extinction, respectively (Fig. 6A,C-H). These observations suggest that monophasic and biphasic ERK activation is required for the reconsolidation-mediated enhancement and extinction of IA 
memory, respectively. It is important to note that ERK functions as an upstream regulator of CREB phosphorylation. Therefore, the transient activation of ERK in the early memory phase may, at least in part, contribute to this phosphorylation of CREB, which activates the expression of genes required for reconsolidation and long-term extinction.

Similar to our previous findings using contextual fear conditioning (Mamiya et al., 2009), CREB was activated in the reconsolidation (amygdala/hippocampus/mPFC) and extinction (amygdala/mPFC) memory phases, while ERK was activated only in the extinction phase at $30 \mathrm{~min}$ after the reactivation session. Consistently, only a single population of $\mathrm{pCREB}^{+} / \mathrm{pERK}^{-}$neurons was observed in the reconsolidation phase, while distinct neuron populations were observed in the extinction phase: $\mathrm{pCREB}^{+} / \mathrm{pERK}^{-}$and $\mathrm{pCREB}^{+} / \mathrm{pERK}^{+}$neurons in the amygdala (Fig. 2); $\mathrm{pCREB}^{-} / \mathrm{pERK}^{+}$neurons in the hippocampus (Fig. 3); and $\mathrm{pCREB}^{+} / \mathrm{pERK}^{-}, \mathrm{pCREB}^{-} / \mathrm{pERK}^{+}$, and $\mathrm{pCREB}^{+} / \mathrm{pERK}^{+}$neurons in the $\mathrm{mPFC}$ (Fig. 4). These observations, especially the contrasting observation of $\mathrm{pCREB}^{-}$/ $\mathrm{pERK}^{+}$and $\mathrm{pCREB}^{+} / \mathrm{pERK}^{-}$neurons, suggest that the activation of CREB and ERK is regulated differently in each brain area when memory is extinguished and that the late phase activation of ERK plays specific and distinct roles for the extinction of fear memory compared with other memory processes such as consolidation and reconsolidation as discussed below. Interestingly, we observed that $\mathrm{pERK}^{+}$neurons were more abundant in the $\mathrm{mPFC}$ compared with the hippocampus and amygdala, since the mPFC showed a higher ratio of $\mathrm{pERK}^{+}$neurons (extinction phase) and $\mathrm{pCREB}^{+}$neurons (reconsolidation phase) compared with the hippocampus and amygdala, suggesting that the activation of ERK in the MPFC plays a more specific role in memory extinction.

It remains unclear whether the same or different populations of neurons are activated in the reconsolidation, transition, and extinction memory phases. A previous study identified the activation of "fear neurons" and "extinction neurons" in the amygdala when cued fear memory is reactivated or extinguished, respectively (Herry et al., 2008). Therefore, it is possible that ERK and CREB are activated in the different populations of neurons with different temporal profiles (i.e., "reconsolidation neurons" and extinction neurons). As discussed above, $\mathrm{pCREB}^{+}$neurons, including $\mathrm{pCREB}^{+} / \mathrm{pERK}^{+}$neurons, may regulate the reconsolidation and long-term extinction of IA memory through the activation of gene expression as reconsolidation and extinction neurons, respectively. Conversely, ERK activation in $\mathrm{pCREB}^{-} / \mathrm{pERK}^{+}$neurons may contribute to the cancellation of CREB-mediated transcriptional activation that would be required for reconsolidation since this ERK activation is specifically observed in the late extinction phase; ERK is activated in the reconsolidation neurons to cancel the activation of gene expression in the extinction phase. Interestingly, a previous study showed that hippocampal ERK activation blocks the induction of c-fos when contextual fear memory is extinguished (Guedea et al., 2011), raising the possibility that this ERK activation antagonizes the CREB-signaling pathway. It is important to identify the neuronal populations that regulate reconsolidation, transition, and extinction and to investigate the molecular signatures and functional significance of those neurons. Additionally, interactions among neural populations identified in this study remains unknown. It is possible that "extinction (transition) neurons" modulate function of reconsolidation neurons to cancel prevent reconsolidation through interactions between them (Eisenberg et al., 2003; Merlo et al., 2014). Therefore, it is also important to examine these interactions in and among the amygdala, mPFC, and hippocampus.

Previously, we showed that the hippocampus displays no change of CREB phosphorylation and Arc expression following extinction learning of contextual fear, and consistently, the inhibition of protein synthesis in the hippocampus in the extinction phase fails to block long-term extinction (Mamiya et al., 2009). These observations have raised the possibility that the hippocampus is not required for long-term extinction. However, we showed that ERK is activated in the hippocampus after the extinction learning of IA memory, and consistently, blocking ERK activation in the hippocampus impairs long-term extinction. Therefore, our current observations indicate essential roles for the hippocampus in memory extinction. Taken together with our previous findings, we suggest that the hippocampus is required for memory extinction but not for a consolidation-like process to stabilize an "extinction memory" through the activation of gene expression.

In the present study, we demonstrated that the reconsolidation, transition, and extinction phases of IA memory show distinct molecular and cellular dynamics of CREB and/or ERK activation in the amygdala, hippocampus, and mPFC. More importantly, we found a transition phase from reconsolidation to extinction that cancels the induction of memory reconsolidation through the activation of ERK signaling, but is insufficient for extinction, suggesting that this active transition process functions as a switch of memory phases by inhibiting reconsolidation. It is important to understand further the molecular and cellular mechanisms underlying the active transition from reconsolidation (fear) to extinction (safety) of fear memory to develop methods for the treatment of emotional disorders such as posttraumatic stress disorder.

\section{References}

Dudai Y (2002) Molecular bases of long-term memories: a question of persistence. Curr Opin Neurobiol 12:211-216.

Dudai Y (2012) The restless engram: consolidations never end. Annu Rev Neurosci 35:227-247.

Duvarci S, Nader K, LeDoux JE (2005) Activation of extracellular signalregulated kinase- mitogen-activated protein kinase cascade in the amygdala is required for memory reconsolidation of auditory fear conditioning. Eur J Neurosci 21:283-289.

Eisenberg M, Kobilo T, Berman DE, Dudai Y (2003) Stability of retrieved memory: inverse correlation with trace dominance. Science 301:11021104.

Fischer A, Radulovic M, Schrick C, Sananbenesi F, Godovac-Zimmermann J, Radulovic J (2007) Hippocampal Mek/Erk signaling mediates extinction of contextual freezing behavior. Neurobiol Learn Mem 87:149-158.

Flood JF, Rosenzweig MR, Bennett EL, Orme AE (1973) The influence of duration of protein synthesis inhibition on memory. Physiol Behav 10:555562.

Frankland PW, Ding HK, Takahashi E, Suzuki A, Kida S, Silva AJ (2006) Stability of recent and remote contextual fear memory. Learn Mem 13:451-457.

Franklin KB, Paxinos G (1997) The mouse brain in stereotaxic coordinates. San Diego: Elsevier Academic.

Fukushima H, Maeda R, Suzuki R, Suzuki A, Nomoto M, Toyoda H, Wu LJ, Xu H, Zhao MG, Ueda K, Kitamoto A, Mamiya N, Yoshida T, Homma S, Masushige S, Zhuo M, Kida S (2008) Upregulation of calcium/calmodulin-dependent protein kinase IV improves memory formation and rescues memory loss with aging. J Neurosci 28:9910-9919.

Fukushima H, Zhang Y, Archbold G, Ishikawa R, Nader K, Kida S (2014) Enhancement of fear memory by retrieval through reconsolidation. Elife 3:e02736.

Gordon WC (1981) Mechanisms of cue-induced retention enhancement. In: Information processing in animals: memory mechanisms (Spear NE, Miller RR, eds), pp 319-339. Hillsdale: Erlbaum. 
Guedea AL, Schrick C, Guzman YF, Leaderbrand K, Jovasevic V, Corcoran KA, Tronson NC, Radulovic J (2011) ERK-associated changes of AP-1 proteins during fear extinction. Mol Cell Neurosci 47:137-144.

Hasegawa S, Fukushima H, Hosoda H, Serita T, Ishikawa R, Rokukawa T, Kawahara-Miki R, Zhang Y, Ohta M, Okada S, Tanimizu T, Josselyn SA, Frankland PW, Kida S (2019) Hippocampal clock regulates memory retrieval via dopamine and PKA-induced GluAl phosphorylation. Nat Commun 10:5766.

Herry C, Trifilieff P, Micheau J, Lüthi A, Mons N (2006) Extinction of auditory fear conditioning requires MAPK/ERK activation in the basolateral amygdala. Eur J Neurosci 24:261-269.

Herry C, Ciocchi S, Senn V, Demmou L, Müller C, Lüthi A (2008) Switching on and off fear by distinct neuronal circuits. Nature 454:600-606.

Impey S, Obrietan K, Wong ST, Poser S, Yano S, Wayman G, Deloulme JC, Chan G, Storm DR (1998) Cross talk between ERK and PKA is required for Ca2 + stimulation of CREB-dependent transcription and ERK nuclear translocation. Neuron 21:869-883.

Ishikawa R, Fukushima H, Frankland PW, Kida S (2016) Hippocampal neurogenesis enhancers promote forgetting of remote fear memory after hippocampal reactivation by retrieval. Elife 5:e17464.

Kida S, Josselyn SA, P, de Ortiz S, Kogan JH, Chevere I, Masushige S, Silva AJ (2002) CREB required for the stability of new and reactivated fear memories. Nat Neurosci 5:348-355.

Kim R, Moki R, Kida S (2011) Molecular mechanisms for the destabilization and restabilization of reactivated spatial memory in the Morris water maze. Mol Brain 4:9.

Lee SH, Choi JH, Lee N, Lee HR, Kim JI, Yu NK, Choi SL, Lee SH, Kim H, Kaang BK (2008) Synaptic protein degradation underlies destabilization of retrieved fear memory. Science 319:1253-1256.

Lewis DJ (1979) Psychobiology of active and inactive memory. Psychol Bull 86:1054-1083

Mactutus CF, Riccio DC, Ferek JM (1979) Retrograde amnesia for old (reactivated) memory: some anomalous characteristics. Science 204:13192130.

Mamiya N, Fukushima H, Suzuki A, Matsuyama Z, Homma S, Frankland PW, Kida S (2009) Brain region-specific gene expression activation required for reconsolidation and extinction of contextual fear memory. J Neurosci 29:402-413.

Merlo E, Milton AL, Goozée ZY, Theobald DE, Everitt BJ (2014) Reconsolidation and extinction are dissociable and mutually exclusive processes: behavioral and molecular evidence. J Neurosci 34:2422-2431.

Merlo E, Milton AL, Everitt BJ (2018) A novel retrieval-dependent memory process revealed by the arrest of ERK1/2 activation in the basolateral amygdala. J Neurosci 38:3199-3207.

Misanin JR, Miller RR, Lewis DJ (1968) Retrograde amnesia produced by electroconvulsive shock after reactivation of a consolidated memory trace. Science 160:554-555.
Myers KM, Davis M (2002) Behavioral and neural analysis of extinction. Neuron 36:567-584.

Nader K, Hardt O (2009) A single standard for memory: the case for reconsolidation. Nat Rev Neurosci 10:224-234.

Nader K, Schafe GE, Le Doux JE (2000) Fear memories require protein synthesis in the amygdala for reconsolidation after retrieval. Nature 406:722-726.

Nomoto M, Takeda Y, Uchida S, Mitsuda K, Enomoto H, Saito K, Choi T, Watabe AM, Kobayashi S, Masushige S, Manabe T, Kida S (2012) Dysfunction of the RAR/RXR signaling pathway in the forebrain impairs hippocampal memory and synaptic plasticity. Mol Brain 5:8.

Pavlov IP (1927) Conditioned reflexes. London: Oxford University Press.

Pedreira ME, Maldonado H (2003) Protein synthesis subserves reconsolidation or extinction depending on reminder duration. Neuron 38:863-869.

Rescorla RA (2001) Experimental extinction. In: Handbook of contemporary learning theories (MowrerRR, KleinS, eds), pp 119-154. Mahwah: Erlbaum.

Schafe GE, Atkins CM, Swank MW, Bauer EP, Sweatt JD, LeDoux JE (2000) Activation of ERK/MAP kinase in the amygdala is required for memory consolidation of Pavlovian fear conditioning. J Neurosci 20:8177-8187.

Schneider AM, Sherman W (1968) Amnesia: a function of the temporal relation of footshock to electroconvulsive shock. Science 159:219-221.

Suzuki A, Josselyn SA, Frankland PW, Masushige S, Silva AJ, Kida S (2004) Memory reconsolidation and extinction have distinct temporal and biochemical signatures. J Neurosci 24:4787-4795.

Suzuki A, Mukawa T, Tsukagoshi A, Frankland PW, Kida S (2008) Activation of LVGCCs and CB1 receptors required for destabilization of reactivated contextual fear memories. Learn Mem 15:426-433.

Suzuki A, Fukushima H, Mukawa T, Toyoda H, Wu LJ, Zhao MG, Xu H, Shang Y, Endoh K, Iwamoto T, Mamiya N, Okano E, Hasegawa S, Mercaldo V, Zhang Y, Maeda R, Ohta M, Josselyn SA, Zhuo M, Kida S (2011) Upregulation of CREB-mediated transcription enhances both short- and long-term memory. J Neurosci 31:8786-8802.

Tronel S, Milekic MH, Alberini CM (2005) Linking new information to a reactivated memory requires consolidation and not reconsolidation mechanisms. PLoS Biol 3:e293.

Tronson NC, Schrick C, Guzman YF, Huh KH, Srivastava DP, Penzes P, Guedea AL, Gao C, Radulovic J (2009) Segregated populations of hippocampal principal CA1 neurons mediating conditioning and extinction of contextual fear. J Neurosci 29:3387-3394.

Wu GY, Deisseroth K, Tsien RW (2001) Activity-dependent CREB phosphorylation: convergence of a fast, sensitive calmodulin kinase pathway and a slow, less sensitive mitogen-activated protein kinase pathway. Proc Natl Acad Sci USA 98:2808-2813.

Zhang Y, Fukushima H, Kida S (2011) Induction and requirement of gene expression in the anterior cingulate cortex and medial prefrontal cortex for the consolidation of inhibitory avoidance memory. Mol Brain 4:4. 